University of South Florida

DIGITAL COMMONS

Digital Commons @ University of

@ UNIVERSITY OF SOUTH FLORIDA

South Florida

USF Tampa Graduate Theses and Dissertations

USF Graduate Theses and Dissertations

January 2015

\title{
Obesity as a Disease: Effects on Weight-Biased Attitudes and Beliefs
}

Rheanna Nichole Ata

University of South Florida, rata@mail.usf.edu

Follow this and additional works at: https://digitalcommons.usf.edu/etd

Part of the Psychology Commons

\section{Scholar Commons Citation}

Ata, Rheanna Nichole, "Obesity as a Disease: Effects on Weight-Biased Attitudes and Beliefs" (2015). USF Tampa Graduate Theses and Dissertations.

https://digitalcommons.usf.edu/etd/5636

This Dissertation is brought to you for free and open access by the USF Graduate Theses and Dissertations at Digital Commons @ University of South Florida. It has been accepted for inclusion in USF Tampa Graduate Theses and Dissertations by an authorized administrator of Digital Commons @ University of South Florida. For more information, please contact digitalcommons@usf.edu. 
Obesity as a Disease: Effects on Weight-Biased Attitudes and Beliefs

by

\author{
Rheanna N. Ata \\ A dissertation submitted in partial fulfillment \\ of the requirements for the degree of \\ Doctor of Philosophy \\ Department of Psychology \\ College of Arts and Sciences \\ University of South Florida \\ Major Professor: J. Kevin Thompson, Ph.D. \\ Jamie Goldenberg, Ph.D. \\ Paul B. Jacobsen, Ph.D. \\ Vicky Phares, Ph.D. \\ Brent J. Small, Ph.D. \\ Date of Approval: \\ April 10, 2015
}

Keywords: weight stigmatization, prejudice, overweight, AMA

Copyright (C) 2015, Rheanna N. Ata 


\section{TABLE OF CONTENTS}

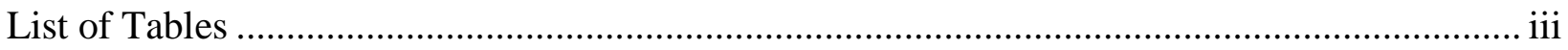

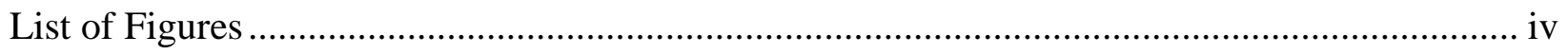

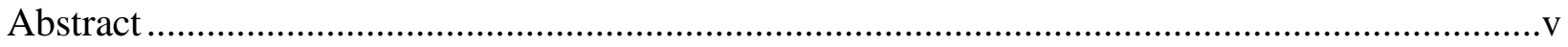

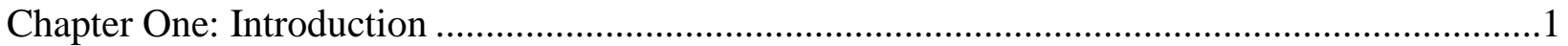

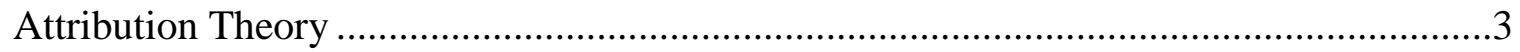

Assessment of Weight Bias …………………………............................................

Implicit versus explicit attitudes ................................................................4

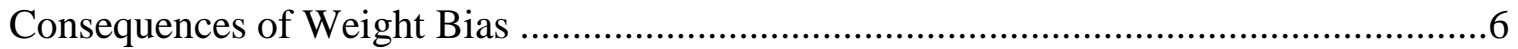

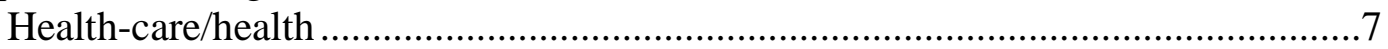

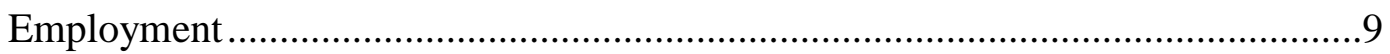

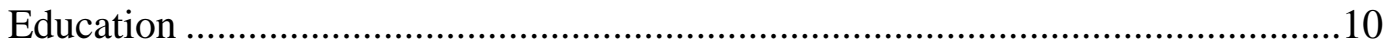

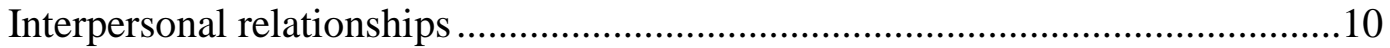

Interventions to Reduce Weight Bias ………………...............................................11

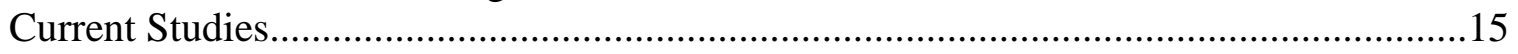

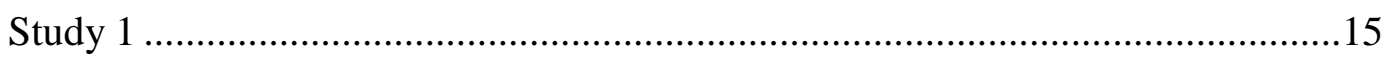

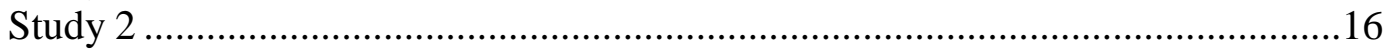

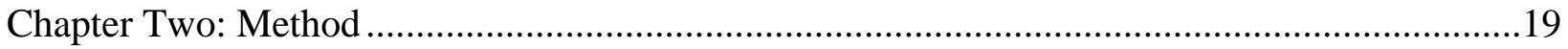

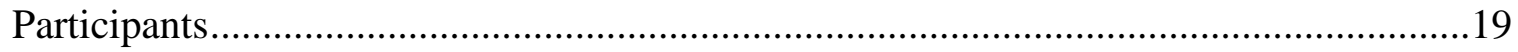

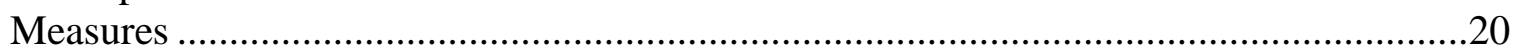

Explicit weight-related attitudes ...................................................................20

Implicit weight-related attitudes ......................................................................20

Beliefs about the controllability of weight........................................................22

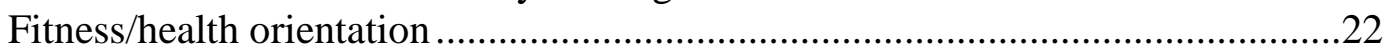

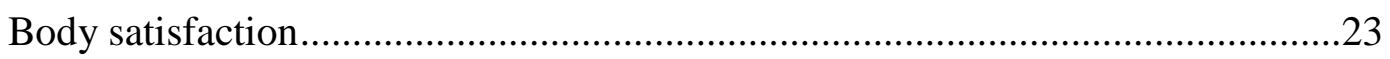

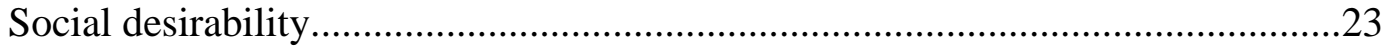

Disease and lifestyle informational articles ...................................................24

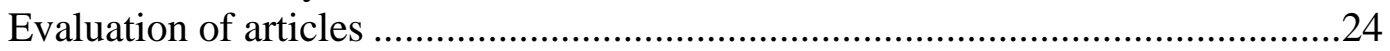

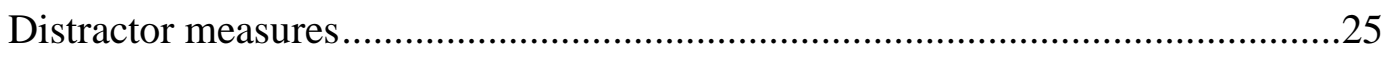

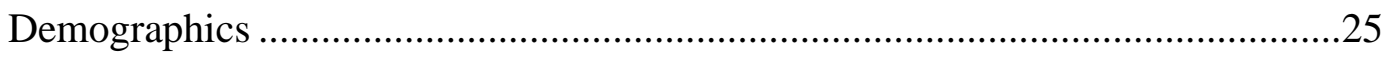

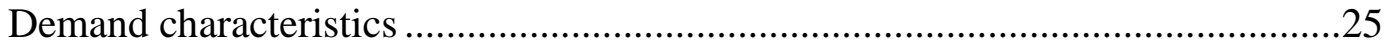

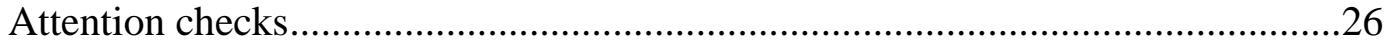

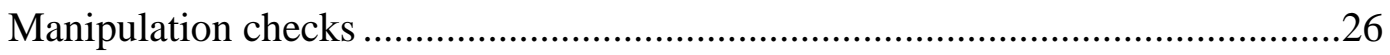

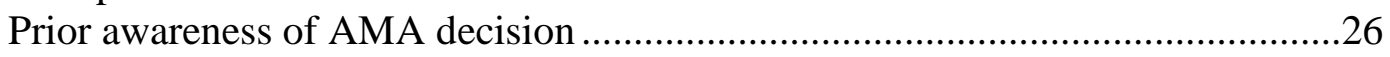

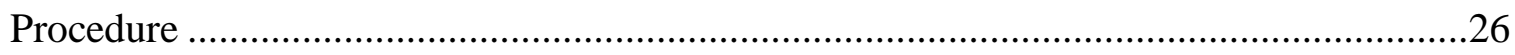




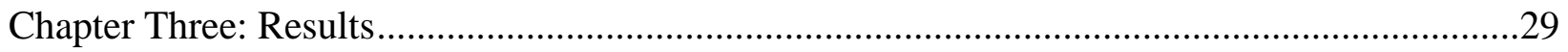

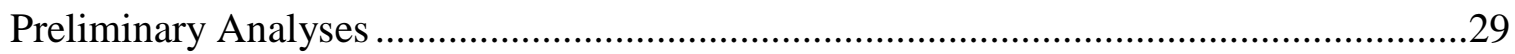

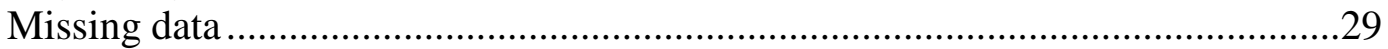

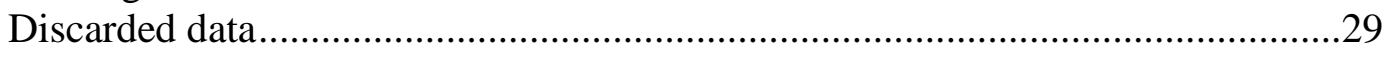

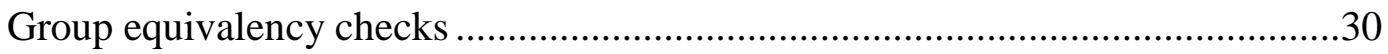

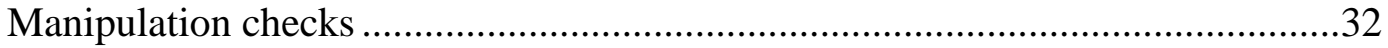

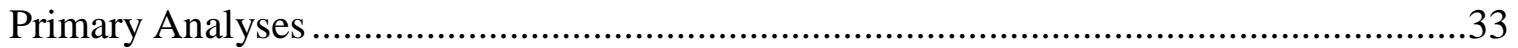

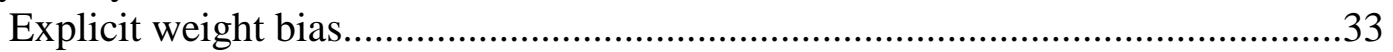

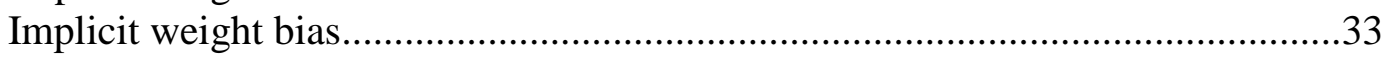

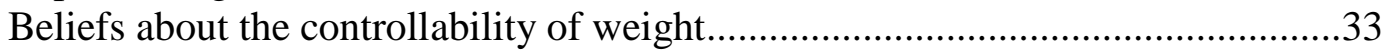

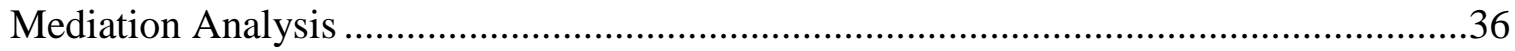

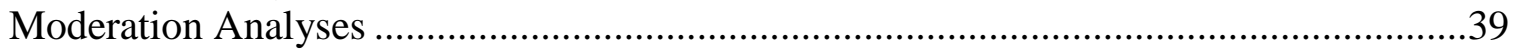

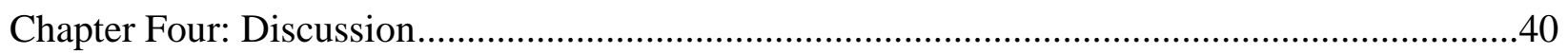

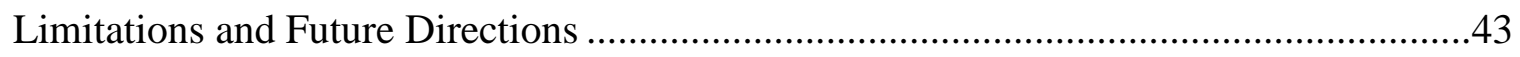

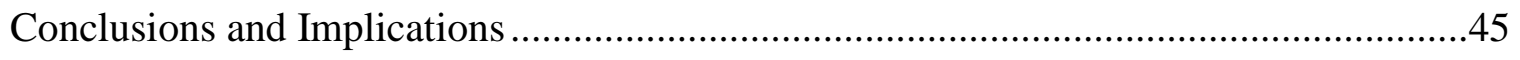

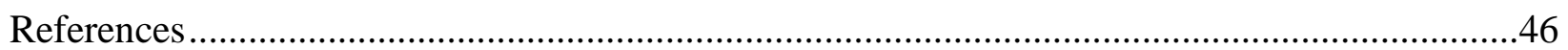




\section{LIST OF TABLES}

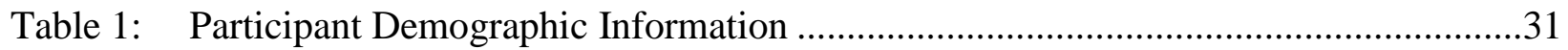

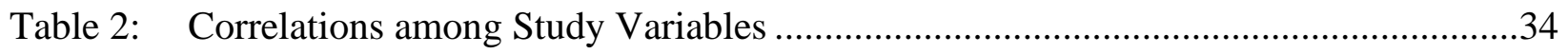

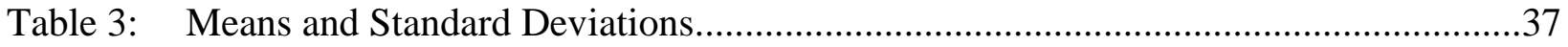




\section{LIST OF FIGURES}

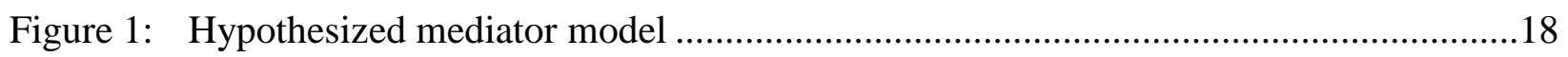

Figure 2: Effects of time and group on beliefs about the controllability of weight ...................35

Figure 3: Change in beliefs about the controllability of weight as a mediator of the relationship between group and explicit weight-biased attitudes (with pre-exposure ATOP score as a covariate) ........................................................... 38 


\begin{abstract}
In June 2013, the American Medical Association (AMA) made the highly controversial decision to designate obesity a disease. Proponents predicted the decision would lead to reduced weightrelated stigma, whereas opponents predicted designating a third of the population as "diseased" would exacerbate stigma. To determine the effects of defining obesity as a disease on explicit and implicit weight-biased attitudes and explicit weight-biased beliefs, female undergraduate students $(N=146)$ were randomly assigned to one of two groups: disease or lifestyle. Participants in the disease group $(n=71)$ were asked to read an article describing obesity as a disease caused by biology and genes; participants in the lifestyle group $(n=75)$ read an article describing obesity as the result of personal choices, including over-consumption of food and inactivity. Explicit weight-biased attitudes and beliefs were measured pre- and post-exposure to the article. Change in beliefs about the controllability of weight was examined as a potential meditator of the relationship between group and explicit weight-biased attitudes; and body mass index (BMI), health orientation, and fitness orientation were examined as potential moderators. Results revealed a significant interaction between group and time on weight-biased beliefs. Participants in the disease group exhibited stronger beliefs that obesity is outside a person's control from pre- to post-exposure, whereas participants in the lifestyle group exhibited a weakening in these beliefs over the same time period. Contrary to hypotheses, this change in beliefs about the controllability of weight did not extend to weight-biased attitudes.
\end{abstract}




\section{CHAPTER ONE:}

\section{INTRODUCTION}

The rate of overweight and obesity in the United States has risen at such an alarming rate over the past 30 years that obesity has been deemed a public health crisis (Wang, Beydoun, Liang, Caballero, \& Kumanyika, 2008). According to national data, 16.9\% of youth and 35.7\% of adults had obesity in 2009-2010 (Ogden, Carroll, Kit, \& Flegal, 2012). Although the prevalence appears to be "leveling off," logistic regression analyses suggest that $42 \%$ of adults will have obesity by 2030 (Finkelstein et al., 2012, p. 563). Obesity, defined as an excess of adipose tissue $\left(B M I \geq 30 \mathrm{~kg} / \mathrm{m}^{2}\right.$ ), was recently designated a disease by AMA (Pollack, 2013).

The consequences of overweight and obesity are many and diverse. From a physical health perspective, obesity has been associated with an increased risk for type II diabetes, hypertension, cardiovascular diseases, stroke, gallbladder disease, respiratory disease, fatty liver disease, musculoskeletal problems, and certain cancers (e.g., endometrial, breast, colon, kidney, and esophageal; Must et al., 1999). Psychosocially, obesity has been linked to poor self-esteem (e.g., Pierce \& Wardle, 1997), depression (in clinical samples only; Henderson \& Brownell, 2004), body dissatisfaction, and disordered eating (e.g., binge eating and/or extreme weight control behaviors; Neumark-Sztainer et al., 2007; Neumark-Sztainer, Wall, Story, \& Sherwood, 2009). It has also been associated with bullying, teasing, and social marginalization in children and adolescents (Haines \& Neumark-Sztainer, 2009). 
One consequence of obesity that has garnered much recent attention is weight bias, which refers to the manner in which "thoughts, feelings, and behaviors may be altered because of [the] stigmatizing mark" of excess weight (Teachman \& Mallett, 2001, p. 122). Weight bias is rooted in a cultural emphasis on thinness, beliefs in a just world, Protestant work ethic, conservative political ideology, and attributes about the controllability of weight (Ebneter, Latner, \& O’Brien, 2011). It is pervasive across weight statuses (Schwartz, Vartanian, Nosek, \& Brownell, 2006; Wang, Brownell, \& Wadden, 2004) and across the lifespan (Hebl, Ruggs, Singletary, \& Beal, 2008). Previous research suggests that individuals with obesity, unlike members of other minority groups, do not exhibit in-group favorability (Crandall, 1994). In fact, patients with obesity at a treatment research clinic endorsed both explicit and implicit weight-biased attitudes and beliefs (Wang et al., 2004). Among a large $(N=4283)$ online sample, explicit and implicit weight bias was reported across the weight spectrum (from underweight to morbidly obese), but there was a negative relation between weight and reported bias (Schwartz et al., 2006).

As a broader phenomenon, weight bias encompasses both weight-based prejudice and discrimination. While weight-based prejudice refers to negative attitudes about individuals with overweight or obesity based on preconceived notions about the weight-related group to which they belong, discrimination is weight bias in the form of observable behaviors (e.g., weightbased teasing; Brownell, 2005). Research suggests that weight/height based discrimination is the third most common form of discrimination experienced by women and the fourth most common form of discrimination reported by American adults (behind discrimination based on gender, race, and age; Puhl, Andreyeva, \& Brownell, 2008). In line with obesity, the prevalence of weight-based discrimination increased by 5\% from 1995-1996 to 2004-2006 (Andreyeva, Puhl, \& Brownell, 2008). 


\section{Attribution Theory}

Attribution Theory (Heider, 1958) provides an etiological explanation for weight bias. According to this theory, our causal explanations about the social world—namely, our attributions - have a significant impact on our emotions and motivation (Crandall \& Reser, 2005). For example, we may infer that a person has obesity because he/she is lazy and lacks willpower, has a genetic vulnerability, eats too much, etc. Our subsequent evaluation of the person is dependent upon the particular inference that we make. When people are held responsible for their negative outcomes, they tend to be the targets of greater negative attitudes. Research suggests that this is true for welfare recipients and those living in poverty; homosexuals; individuals suffering from HIV/AIDS, depression, or alcohol dependence; survivors of spousal abuse, rape, or sexual harassment; African-Americans, Asians, Jews, and women (Crandall \& Reser, 2005). This theory is further borne out in research that suggests the more people believe weight is attributable to factors within an individual's control (e.g., willpower, physical activity), the stronger the weight-biased attitudes they express (Cahnman, 1968; Crandall, 1994; DeJong, 1980; McClure, Puhl, \& Heuer, 2011; Weiner, Perry, \& Magnusson, 1988). Conversely, obesity stigma is negatively associated with "germ or virus" causal beliefs (McClure et al., 2011).

Attribution-value theory, an extension of Attribution Theory, posits that prejudice results from two factors: "(1) a judgment that the group or characteristic has a negative cultural value (e.g., fat is a 'bad thing'), and (2) attributions of responsibility" (Crandall \& Reser, 2005, p. 89). Thus, the model suggests that being held personally responsible for a negative outcome or characteristic results in prejudice. Cross-cultural research suggests that weight-biased attitudes and beliefs are more common in countries that extoll individualism and emphasize personal 
responsibility (e.g., United States) than countries that are more collectivist in nature (e.g., India; Crandall et al., 2001). High levels of weight-biased attitudes within the United States, then, may be attributable to simultaneous denigration of fatness and idealization of thinness. Individuals who value fitness and health are likely to endorse weight-biased attitudes_provided that they also deem people with obesity personally responsible for their weight. In males, a strong orientation to fitness and health is positively correlated with scores on the Weight Control/Blame subscale of the AFAT, higher scores on which are indicative of a belief that excess weight is due to a lack of willpower and poor eating habits, as opposed to biological or genetic factors (Lewis, Cash, \& Bubb-Lewis, 1997).

\section{Assessment of Weight Bias}

Weight bias is a multidimensional construct. The focus of the current study, weight-based prejudice, is made up of an attitudinal component and a beliefs component. The attitudinal component encompasses mental positions/opinions about persons with obesity, while the beliefs component encompasses views about how obesity is developed and maintained. These constructs are related but distinct, as evidenced by a correlation of $r=.40$ between scores on companion measures of weight-related attitudes and beliefs: the Attitudes Toward Obese Persons Scale (ATOP; Allison, Basile, \& Yuker, 1991) and Beliefs about Obese Persons Scale (BAOP; Allison et al., 1991).

Implicit versus explicit attitudes. Attitudes toward people with overweight and obesity are theorized to exist both within and outside of conscious awareness. Face valid self-report questionnaires, semantic differential scales, and feeling thermometers are commonly used to 
assess consciously held or explicit attitudes (Cunningham, Preacher, \& Banaji, 2001). The use of such measures is based on the assumption that individuals are both able and willing to accurately report their beliefs and attitudes, which does not always hold true (Greenwald \& Banaji, 1995). Individuals may censor reports of explicit attitudes due to a wish to respond in a socially desirable manner and appear unbiased. Alternatively, "people who wish to be unbiased may still be affected by societal messages, and may not realize that they hold negative attitudes;" thus, it may be more of an inability, as opposed to an unwillingness, to access such attitudes via explicit recall (Grover, Keel, \& Mitchell, 2003; Teachman \& Brownell, 2001, p. 1526; Teachman \& Mallett, 2005).

Given that implicit attitudes are automatic, "introspectively unidentified," and therefore inaccessible for recall (Greenwald \& Banaji, 1995, p. 5), attitudes that reside outside of conscious awareness must be assessed via indirect measures. Perhaps one of the most widely used implicit measures is the Implicit Association Test (IAT; Greenwald, McGhee, \& Schwartz, 1998). The IAT is a timed sorting task used to measure automatic, memory-based preferences or associations. In the computerized weight-related attitudes version of the IAT, participants are first shown "thin" or "fat" silhouettes and asked to categorize them, as quickly as possible, into categories (e.g., "Fat People" or "Thin People"). They are then presented with words (e.g., agony, peace, hurt) and asked to categorize them into "Good" or "Bad." In the next two trials, "Fat People" is paired with "Good" and "Thin People" is paired with "Bad." Participants must press one key (i.e., "E") on their keyboard to place words or images into the fat or good category and another (i.e., "I") to place them into the thin or bad category. The entire process then starts over, with the initial categories on opposite sides of the screen, so that in the final two trials "Fat People" is paired with "Bad" and "Thin People" is paired with "Good." 
The measure of implicit attitudes is obtained by calculating the difference in response latency when "Thin People" and "Good" words are classified with the same key versus when "Fat People" and "Good" words are classified with the same key. To the extent that the pairing is consistent with a participant's automatic associations about people with obesity, response latency should be decreased. Thus, a participant is deemed to hold implicit weight-biased attitudes if they are quicker to respond when "Thin People" is paired with "Good" than when "Fat People" is paired with "Good." In general, IAT measures of attitude tend to correlate weakly with explicit measures of the same attitude (Greenwald \& Nosek, 2001). In fact, research supports the notion that an individual who does not endorse weight-biased attitudes may still exhibit implicit bias. In one study, health-care professionals ( $72 \%$ physicians) attending a workshop on the stigma of obesity exhibited strong implicit biases against individuals who were overweight, despite reporting low levels of explicit bias on a semantic differential scale task that asked them to rate their feelings about "fat people" and "thin people" as bad versus good, lazy versus motivated, etc. (Teachman \& Brownell, 2001). In samples of medical students ( $N=310$; Miller et al., 2013) and health care professionals $(N=84$; Teachman \& Brownell, 2001), explicit and implicit weight-related biases were not significantly correlated $(r=.03, p=.58$ and $r=.06, p>.10$, respectively). Thus, it may be important for researchers to obtain both explicit and implicit measures of weight bias.

\section{Consequences of Weight Bias}

Recent reviews of the extant literature suggest that weight bias is ubiquitous across all social contexts (e.g., health-care, employment, education, interpersonal relationships) and is 
linked to a host of adverse behavioral, psychosocial, and physical outcomes (Puhl \& Brownell, 2001; Puhl \& Heuer, 2009).

Health-care/health. Research indicates that the most common perpetrators of weightrelated stigma are friends, strangers, spouses, family members, and health professionals (Puhl, Moss-Racusin, Schwartz, \& Brownell, 2008). Among women with overweight or obesity, physicians have been reported as the second most common source of stigma (Puhl \& Brownell, 2006). Health-care professionals — ranging from physicians and psychologists to medical and dietetic students - exhibit weight-biased attitudes and make personal responsibility attributions of obesity (Puhl \& Brownell, 2001; Puhl \& Heuer, 2009). Research suggests that patients with overweight or obesity are commonly described by these professionals as unattractive, lazy, undisciplined, and noncompliant. Further, experimental research suggests a linear relationship between a patient's weight and a physician's desire to help him/her (Hebl \& Xu, 2001).

Perhaps the most salient consequences of weight bias are those that may impact the weight management efforts and overall health of individuals with obesity. As noted above, health care professionals possess weight-biased attitudes and beliefs that may impact the experiences of people with obesity in health-care settings. Another form of weight bias to which patients with obesity are subject relates to the size of medical equipment. In one qualitative study, $41 \%$ of women $\left(25 \leq \mathrm{BMI} \leq 122 \mathrm{~kg} / \mathrm{m}^{2}\right)$ reported that they had delayed seeking health care or gynecological cancer-screening examinations (e.g., Pap smears) because of their weight; this number increased to $68 \%$ in women with a BMI greater than $55 \mathrm{~kg} / \mathrm{m}^{2}$ (Amy, Aalborg, Lyons, \& Keranen, 2006). Avoidance of mammograms among women with obesity has also been reported in a more recent qualitative study (Freidman, Hemler, Rossetti, Clemow, \& Ferrante, 2012). 
Specific weight-related biases noted included negative weight-related commentary from providers; embarrassment associated with being weighed; and unaccommodating gowns, exam tables, and blood pressure cuffs (Amy et al., 2006; Friedman et al., 2012). In adults (females and males) in Switzerland, overweight and obesity have also been associated with lower rates of screening for colorectal cancer (Fischer et al., 2013). These findings are particularly disconcerting, given that obesity has been linked to increased risk of colorectal and breast cancers (Must et al., 1999).

Exposure to weight bias has also been associated with engagement in behaviors that contribute to further weight gain and, therefore, increased risk for health concerns. In one study, a modest sample of participants who were overweight $(n=34)$ or normal weight $(n=39)$ were randomly assigned to view either a weight stigmatizing or a neutral video (Schvey, Puhl, \& Brownell, 2011). Women with overweight who watched the stigmatizing video consumed significantly more calories post-exposure than women who were normal weight across conditions and three times as many calories as women with overweight in the neutral condition (Schvey et al., 2011). Similarly, correlational research has linked activation of negative weightrelated stereotypes to increased caloric intake (Campbell \& Mohr, 2011) and lower dietary/exercise health intentions (Seacat \& Mickelson, 2009). Weight-related stigmatization has been associated with a greater desire to avoid exercise and less frequent engagement in moderate and strenuous exercise in college-aged women (Vartanian \& Shaprow, 2008).

Weight bias has also been associated with increased use of mental health services (Puhl $\&$ Heuer, 2009). Lifetime experiences of weight stigmatization are associated with poor selfesteem and body dissatisfaction (Annis, Cash, \& Hrabosky, 2004), as is the presence of implicit weight bias in individuals with overweight and obesity (Gumble \& Carels, 2012). In addition to 
poor self-esteem and body dissatisfaction, a weight-based childhood teasing history has been linked to depression, weight and shape concerns, and shame in weight-loss surgery candidates (Rosenberger, Henderson, Bell, \& Grilo, 2007). Weight-based teasing has also been linked to disordered eating behaviors in adolescents both concurrently and longitudinally. In one longitudinal study of adolescents, weight-related teasing at baseline predicted lower self-esteem and higher levels of body dissatisfaction and depressive symptomatology in females and males five years later (Eisenberg, Neumark-Sztainer, Haines, \& Wall, 2006).

In a recent meta-analysis of 57 published and unpublished studies on appearance-related teasing, moderate weighted mean effects sizes were obtained for the relationships between body dissatisfaction and weight-related (.39) and appearance-related (.32) teasing (Menzel et al., 2010). Effect sizes of a similar magnitude provided support for the relationship between weightrelated teasing and disordered eating pathology, namely dietary restraint (.35) and bulimic behaviors (.36). Moderation analyses on type of study (i.e., correlational or longitudinal) revealed a potential causal link between teasing and body dissatisfaction (Menzel et al., 2010). Existing research suggests that body dissatisfaction may mediate the relationship between weight-related teasing, specifically, and disordered eating among some women (Reddy \& Crowther, 2007).

Employment. Victims of discrimination in the workplace commonly attribute it to their weight and appearance (Puhl \& Brownell, 2001; Puhl \& Heuer, 2009). Compared to individuals of normal weight, individuals with overweight or obesity are viewed as less conscientious, extraverted, agreeable, and emotionally stable. Individuals with overweight or obesity self-report being the targets of weight bias by co-workers and supervisors. They are less likely to be hired or 
promoted and more likely to receive higher wage penalties or be wrongfully terminated. Metaanalytic results provide evidence for a causal link between weight bias and hiring decisions (Roehling, Pilchwe, Oswald, \& Bruce, 2008). They further suggest that White individuals are more likely to be discriminated against than their African American counterparts, but men and women are equally likely to experience weight-related workplace discrimination.

Education. Stigmatization in the education setting is perceived from teachers, peers, and parents (Puhl \& Brownell, 2001; Puhl \& Heuer, 2009). At higher levels of education, individuals with overweight and obesity are less likely to gain acceptance into or attend college and more likely to face dismissal due to weight than their counterparts of normal weight. Parents are less likely to provide financial support to their heavier college-bound daughters (Puhl \& Brownell, 2001).

Interpersonal relationships. In addition to familial relationships, individuals with overweight and obesity encounter weight bias in friendships and romantic relationships (Puhl \& Brownell, 2001; Puhl \& Heuer, 2009). One experimental study found that men were more likely to respond to a personal advertisement describing a woman with a history of drug abuse than one in which a woman was identified as obese (Sitton \& Blanchard, 1995). In another study, a person with obesity was ranked as the least desirable sex partner, behind people with various physical disabilities (e.g., a missing arm) and a person with a history of sexually transmitted infections (Chen \& Brown, 2005). Not surprisingly, then, women with overweight and obesity are less likely to be in a romantic relationship than their peers who are thin (Puhl \& Brownell, 2001; Puhl $\&$ Heuer, 2009). For those in relationships, body weight is negatively associated with 
relationship satisfaction. Weight does not appear to play such a salient role in the romantic relationships of men with overweight and obesity.

\section{Interventions to Reduce Weight Bias}

Given the myriad negative outcomes associated with weight bias, there has been a recent focus within the field on the development of interventions aimed at reducing weight-biased attitudes and beliefs. A majority of existing weight bias reduction interventions can be classified into one of three categories: controllability, empathy, or social consensus.

Based on Attribution Theory (Heider, 1958)—which argues that our causal explanations or attributions impact our attitudes and feelings - causality or controllability interventions aim to change participants' beliefs about the degree to which a person's weight is under his/her control. Participants in controllability intervention are typically exposed to explanations of obesity that emphasize either genetic (e.g., abnormal appetite regulation caused by a genetic mutation) or behavioral (e.g., unhealthful diet) factors. Those in the genetic condition are expected to experience a post-exposure decrease in weight bias. In one such study, community-dwelling adults of normal weight were recruited online and randomly assigned to read a passage outlining the causes of obesity as either genetic, environmental, or the result of a gene-environment interaction (Lippa \& Sanderson, 2012). Completion of measures designed to assess obesity stigma and causal beliefs about obesity followed. Results suggested that participants in the genetic and gene-environment interaction conditions were more likely to believe that genetics increase risk for obesity than participants in the other groups, but the effect of condition on obesity stigma (measured post-exposure only) was non-significant. 
Empathy interventions aim to reduce weight bias by encouraging perspective-taking and increasing feelings of empathy, acceptance, or liking. To this end, participants are commonly asked to watch videos of individuals describing personal experiences with weight bias (e.g., Gapinski, Schwartz, \& Brownell, 2006) or read first-person narratives on social rejection (e.g., Teachman, Gapinski, Brownell, Rawlins, \& Jeyaram, 2003). Participants in one study were randomly assigned to receive a discrimination prime or no prime prior to completing measures of explicit and implicit weight bias (Teachman et al., 2003). Those in the discrimination prime condition were asked to read a story of severe weight-based discrimination based on an actual news story about a girl who died at a weight loss camp after being verbally abused and forced to engage in outdoor exercise in hot weather. Results indicated a significant decrease in implicit bias in participants who were overweight and randomized to the discrimination prime condition. The manipulation did not appear to have an effect on weight bias in participants of normal weight.

Social consensus interventions are based on the idea that perceptions of the attitudes and beliefs of others (i.e., social consensus information) have a significant impact on the development and maintenance of personal attitudes and beliefs (Sechrist \& Stangor, 2005). In one study that attempted to reduce weight bias via exposure to social consensus information, participants completed two visits (Ciao \& Latner, 2011). During the first visit, they were told that they would be participating in a study on the effects of values on cognitions and behaviors toward social groups. They were further informed that they would be randomly assigned to answer questions about one of nine groups (e.g., individuals with obesity, athletes, Scientologists); in reality, they were all assigned to the individuals with obesity group and subsequently instructed to complete the baseline questionnaires. 
During the second visit, participants were informed that their responses had been entered into a system that provided personalized feedback. At this point, participants were randomized to one of three conditions: cognitive dissonance, social consensus, or control. In the cognitive dissonance condition, participants' feedback reports stated that they had reported robust values (particularly Universalism and Benevolence) and very negative attitudes toward people with obesity. They were further informed that these scores were inconsistent, given that individuals who score high on Benevolence and Universalism are typically highly accepting of others. In the social consensus condition, participants did not receive feedback with regard to their values, but were told that they held strong negative attitudes (i.e., within the $12^{\text {th }}$ percentile) toward people with obesity. According to the feedback report, other students at their university had much more favorable views of individuals with obesity (quantified as an average score 63 points higher than the fake individual score). In the control condition, participants were told that their values and attitudes about people with obesity were consistent with each other and within the normal range. Having read the feedback report, participants again completed a measure of weight bias. In this particularly study, providing social consensus information was not efficacious; results indicated a significant difference in weight bias scores in the cognitive dissonance condition (lower) versus control condition only.

Other programs designed to reduce weight bias have included size acceptance/sensitivity training (e.g., Hague \& White, 2005), counter-conditioning (portraying people with obesity in a positive light; e.g., Gapinski et al., 2006), manipulated portrayals of people with obesity (e.g., McClure et al., 2011), a self-esteem and body image program (e.g., Robinson, Bacon, \& O’Reilly, 1993), viewing of anti-stigma films (e.g., Swift et al., 2013), and/or completion of a service learning project (Rukavina, Li, \& Rowell, 2008; Rukavina, Li, Shen, \& Sun, 2010). 
A recent review (Daníelsdóttir, O’Brien, \& Ciao, 2010) of the extant literature on weightbiased prejudice reduction studies lamented the general scarcity of research on the topic and methodological flaws in the existing studies that preclude the interpretation of results. The authors conclude their review by calling for additional, methodologically rigorous research in the area. In an attempt to further examine the impact of existing weight bias reduction interventions, Lee, Ata, and Brannick (2014) conducted a meta-analysis. Thirty-nine effect sizes for weightbiased attitudes and 20 effect sizes for weight-biased beliefs were extracted from 29 studies. Results revealed a small to medium effect of weight bias interventions on both weight-biased attitudes (Hedges' $g=-0.33, p<.001 ; 95 \% \mathrm{CI}=[-0.42,-0.24])$ and beliefs $(g=-0.33, p<.001$; $95 \% \mathrm{CI}=[-0.50,-0.15])$. Moderator analyses for weight-biased attitudes were not significant for publication type (i.e., journal article or thesis/dissertation), type of intervention (e.g., controllability), or study population (e.g., students, health professionals/health professionals intraining). Overall results suggest that, to date, interventions designed to reduce weight bias have had a small but positive effect on explicit weight-biased attitudes and beliefs.

The effect of interventions on implicit weight-biased attitudes is less clear. Overall, there seems to be a paucity of intervention studies that have included both explicit and implicit measures of weight bias. Of the studies that have measured explicit and implicit weight bias, one study found a significant effect of weight bias reduction interventions on implicit bias (in participants with overweight only; Teachman et al., 2003), while other studies have revealed significant reductions in explicit but not implicit weight bias (Rukavina et al., 2010; Swift et al., 2013). 


\section{Current Studies}

The decision made by the AMA remains hotly contested, with proponents of the pronouncement contending that labeling obesity a disease may reduce weight-related stigma (Katz, 2014; Pollack, 2013) and opponents predicting that it will have the opposite effect (Garrey, 2013). While various interventions have been developed to decrease weight bias, an overall scarcity of research and mixed findings substantiate the need to test new stigma-reduction methods (Schwartz \& Puhl, 2005). Unlike interventions confined to the laboratory, defining obesity as a disease has the potential to exert real, far-reaching effects on popular attitudes and beliefs about obesity.

Study 1. An initial feasibility study was conducted with both male and female participants $(N=154)$. In this study, participants were randomly assigned to read an article defining obesity as a disease versus a control article about obesity. The articles were similar in length and style. The first article noted the AMA's decision to designate obesity as a disease. It also outlined the potential negative health consequences of overweight/obesity and possible consequences of the AMA decision. The second (control) article, based on fact sheets created by the World Health Organization (WHO; 2013) and the American Heart Association (AHA; 2013), did not make any mention of obesity as a disease. Rather, it defined overweight/obesity, provided prevalence estimates for the United States and world, and outlined negative health consequences and treatment options. To ensure that participants attended to the content of the articles, they were asked a series of factual, multiple choice questions (e.g., "Which state in the United States has the highest prevalence of obesity?"). As a manipulation check, participants 
were also asked to respond to a true/false item (i.e., "According to the article you read, obesity is a disease.").

Prior to analyzing the data, frequencies of participants who passed versus failed the manipulation check were obtained. Approximately $92 \%$ of participants who were randomized to the obesity as a disease group $(n=72)$ passed the manipulation check by choosing the "true" response option. Of participants who were assigned to the control group $(n=82)$, only $18 \%$ passed the manipulation check by choosing the "false option." These findings did not appear to be due to participant inattention, as $80 \%$ of participants correctly responded to each of the article-based factual questions. While it is unclear why participants in both groups tended to respond in a manner consistent with having viewed the obesity as a disease article, results suggested that the manipulation was ineffective. Preliminary analyses indicated a significant effect of time $(F(1,114)=12.70, p<.01)$, and non-significant effects of group $(F(1,114)=1.01$, $p=.32)$ and gender $(F(1,114)=1.25, p=.27)$, on explicit weight-biased attitudes.

Study 2. The following study was designed in an attempt to strengthen the manipulation by comparing the article defining obesity as a disease to an article defining obesity as the result of lifestyle choices. Given the lack of a gender effect in Study 1, and difficulty obtaining a sizeable male sample, Study 2 was restricted to female participants. Study 2 sought to determine whether presenting obesity as a disease would affect explicit weight-biased attitudes and beliefs in college-aged women who were randomly assigned to read an article mentioning the recent AMA decision and defining obesity as a disease resulting from biology and genes versus an article defining obesity as the result of eating- and exercise-related personal choices. Five main hypotheses and two exploratory research questions were proposed: 
1. Participants in the obesity as a disease condition will exhibit a significant decrease in explicit weight-biased attitudes from pre- to post-exposure when compared to participants in the lifestyle condition.

2. Participants in the obesity as a disease condition will exhibit a significant increase in beliefs about the controllability of weight as compared to participants in the lifestyle condition.

3. The relationship between condition (disease v. lifestyle) and explicit weightbiased attitudes will be mediated by change in beliefs about the controllability of weight (Figure 1).

4. Fitness/health orientation will moderate the effect of condition on explicit weightbiased attitudes, such that participants who report lower levels of fitness/health orientation will exhibit a greater decrease in weight-biased attitudes from pre- to post-manipulation than those who report higher levels of fitness/health orientation.

Exploratory Research Question 1: Will a disease versus lifestyle exposure differentially affect implicit weight-biased attitudes?

Exploratory Research Question 2: Will BMI moderate the effect of condition on explicit weight-biased attitudes? 


\section{Direct Effect}

\begin{tabular}{|c|c|c|}
\hline $\begin{array}{c}\text { Group: } \\
\text { Disease v. lifestyle }\end{array}$ & $\begin{array}{c}\text { Outcome: } \\
\text { Explicit weight bias }\end{array}$ \\
\hline
\end{tabular}

\section{Indirect Effect}

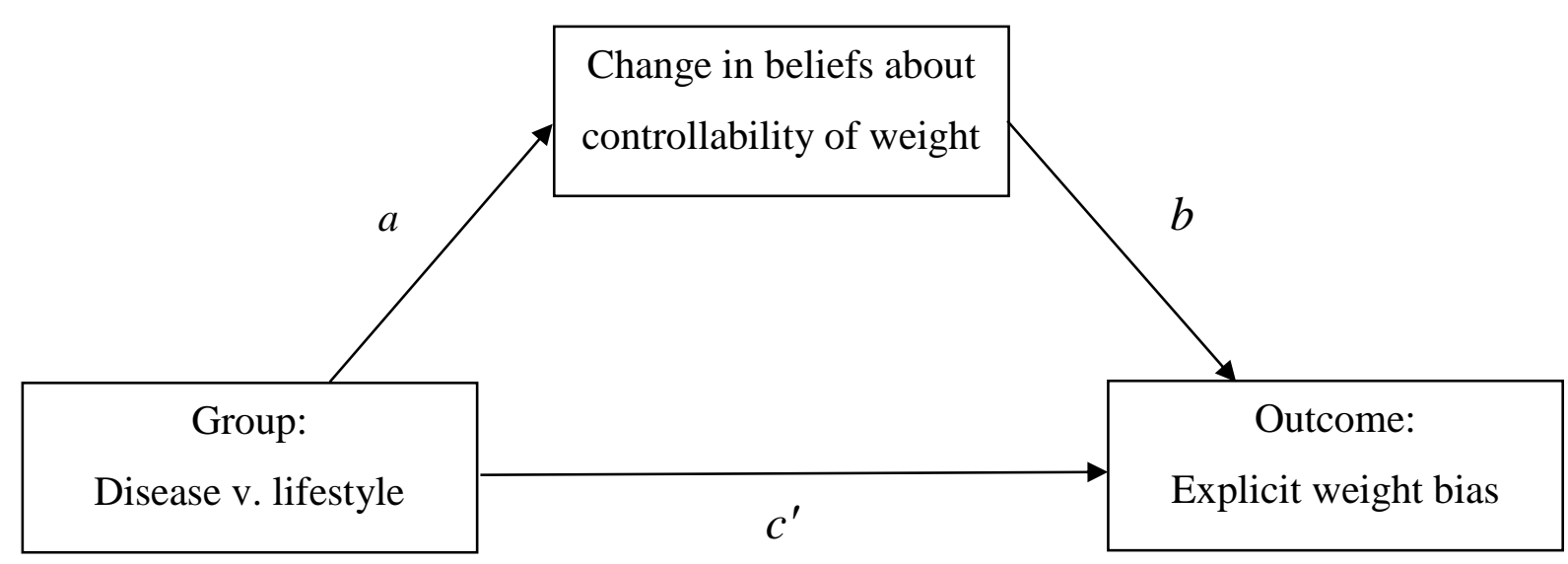

Figure 1. Hypothesized mediator model 


\section{CHAPTER TWO:}

\section{METHOD}

\section{Participants}

A total of 150 female participants were recruited for the current study via the University of South Florida's undergraduate participant pool (SONA). This sample size was based on results of a power analysis, which indicated that a minimum of 64 participants per cell was required to detect a medium effect with alpha set at .05 and .80 power. Additional participants were recruited to account for unusable data due to program errors. Eligible participants, who were at least 18-years-old, were enrolled in at least one undergraduate psychology course, able to give informed consent, and fluent in English. Extra credit (i.e., SONA points) was awarded to participants in exchange for their participation.

Participants ranged in age from 18 to 64 years $(M=19.84, S D=4.82)$; the modal age was 18 years. Over half of participants (56.8\%) identified as White/Caucasian. Remaining participants self-identified as African-American or Black (19.9\%), Asian or Asian American (7.5\%), multiracial (5.5\%), or other (10.3\%). Approximately a quarter of participants endorsed being Hispanic/Latina (25.3\%). Self-reported height and weight were used to calculate BMI; the mean BMI for the sample was $23.23(S D=4.64)$, which falls in the "normal weight" range (BMI $=18.50-24.99 ;$ WHO, 2003). Consistent with the mean BMI, a majority of participants (64.4\%) described their current weight as "healthy." Perceived weight status was highly correlated with BMI-based weight category $(r=.69)$. 


\section{Measures}

Explicit weight-related attitudes. Participants' attitudes toward people with obesity were measured using the Attitudes Toward Obese Persons Scale (ATOP; Allison et al., 1991). The ATOP was modeled after the Attitudes towards Disabled Persons Scale (ATDP; Yuker \& Block, 1986). It consists of 20 items rated on a six-point Likert-type scale. Response options ranged from I strongly disagree (-3) to I strongly agree (+3). Scores can be obtained for each of three subscales: Different Personality (e.g., “Obese people are as happy as non-obese people.”), Social Difficulties (e.g., "Obese people tend to have family problems.”), and Self-Esteem (e.g., “Most obese people resent normal weight people.”). Higher scores (range $=0-120$ ) are associated with more negative attitudes toward people with obesity. Internal consistency estimates for the ATOP range from $\alpha=.80$ (undergraduate sample) to $\alpha=.84$ (National Association to Advance Fat Acceptance sample). In the current sample, $\alpha=.67$ for pre-ATOP and $\alpha=.86$ for post-ATOP.

Implicit weight-related attitudes. The Implicit Association Test (IAT; Greenwald et al., 1998) is a timed sorting task used to measure automatic, memory-based preferences or associations. In the current study, a free, open-source program (i.e., FreeIAT) was used to assess implicit weight-bias (Meade, 2009). To that end, the program was customized to include two sets of stimuli: images (“fat" versus "thin"; Nosek et al., 2007) and words ("good" versus "bad").

The FreeIAT program administers the IAT in five stages, each consisting of multiple trials. In Stage 1, images of faces edited to appear "fat" or "thin" appear in the center of the screen; participants are instructed to categorize them into the "fat" or "thin" category. Each 
category is presented on a different side of the computer screen; the " $\mathrm{E}$ " key is used to sort stimuli into the category presented on the left-hand side of the screen, while the "I" key is used to sort stimuli into the category on the right-hand side of the screen. The stimuli are randomly selected for presentation (the same stimulus may not appear in succession; Meade, 2009). A large, red "X" appears on the screen following an incorrect response, and participants cannot proceed until they answer correctly. For each trial, the program automatically records the response time (in milliseconds) and whether the participant answered correctly (Meade, 2009). Stages 2 and 4 are also learning trials, wherein participants practice correctly categorizing the images or words.

Stages 3 and 5 involve paired comparisons of the target and attribute. During one of these stages, the images and words are paired in a manner consistent with weight bias (e.g., images of "fat" people are classified with the same key as "bad" words); during the other stage, the pairing is inconsistent with weight bias (e.g., images of "fat" people are classified with the same key as "good" words). The so-called IAT effect is based on differences in reaction time between the mismatched condition (e.g., images of "fat" people and "good") and the matched condition (e.g., images of "fat" people and "bad"). FreeIAT automatically calculates individual IAT scores, using the scoring algorithm recommended by Greenwald, Nosek, and Banaji (2003), and presents them in a separate output file.

While there appears to be a dearth of research on the specific measurement properties of the weight-related IAT, the IAT, in general, boasts greater reliability than other implicit measures, with internal consistency estimates (split-half or Cronbach's alpha) ranging from .70 to .90 (Nosek, Greenwald, \& Banaji, 2007). Test-retest reliability appears to be fairly stable across studies with 0-100 days between administrations (median $r=.56$ ). Cronbach's alpha for 
the current sample was calculated by correlating the IAT score computed using the first half of the stimuli from Stages 3 and 5 with the IAT score computed using the last half of the stimuli from Stages 3 and 5 ( $r=.57$; Meade, 2009).

Beliefs about the controllability of weight. The extent to which participants believe that obesity/weight is controllable was assessed using the Beliefs about Obese Persons Scale (BAOP; Allison et al., 1991). The BAOP is the companion scale to the ATOP, and the two are positively correlated ( $r=.40$; Allison et al., 1991). Participants were asked to rate each of the eight items (e.g., "Obesity is usually caused by overeating.") on a six-point Likert-type scale ranging from $I$ strongly disagree $(-3)$ to I strongly agree $(+3)$. Higher scores (range $=0-48)$ indicate a stronger belief that obesity is not under the person's control. Reliability estimates for the BAOP range from $\alpha=.65$ (undergraduate sample) to $\alpha=.82$ (NAAFA sample). Internal consistency of the pre-BAOP in the current sample was $\alpha=.74$; post-BAOP $\alpha=.77$.

Fitness/health orientation. The Multidimensional Body-Self Relations Questionnaire (MBSRQ; Brown, Cash, \& Mikulka, 1990) is a 69-item questionnaire that provides a multidimensional assessment of the attitudinal component of body image. For the purposes of the current study, the Fitness Orientation (MBSRQ-FO) and Health Orientation (MBSRQ-HO) subscales were administered. Both orientation subscales assess the degree of importance and attention an individual gives to the specific physical domain (e.g., health or fitness), as well as his/her engagement in behaviors related to maintaining or improving his/her standing within that domain. The MBSRQ-FO consists of 13 items (e.g., "I do things to increase my physical strength.”); the MBSRQ-HO consists of 8 items (e.g., "I have deliberately developed a healthy 
lifestyle.”). For both subscales, participants were asked to rate each item on a five-point Likerttype scale ranging from definitely disagree (1) to definitely agree (5). Negatively-worded items (e.g., "I do not actively do things to keep physically fit.") were reverse-scored and responses were averaged to obtain subscale scores. Higher scores are indicative of greater personal investment in fitness or health. The MBSRQ-FO has demonstrated adequate reliability in a prior undergraduate sample of females $(\alpha=.89$; Brown et al., 1990). In the same undergraduate sample, $\alpha=.78$ for the MBSRQ-HO (Brown et al., 1990). In the current sample, internal consistency was $\alpha=.92$ for the MBSRQ-FO and $\alpha=.78$ for the MBSRQ-HO.

Body satisfaction. The Appearance Evaluation subscale of the Multidimensional BodySelf Relations Questionnaire (MBSRQ-AE; Brown et al., 1990) was used to measure body satisfaction. This subscale contains seven items (e.g., "Most people would consider me good looking") and instructs participants to rate their feelings of physical attractiveness on a five-point Likert-type scale. Response options range from definitely disagree (1) to definitely agree (5). Negatively worded items (e.g., "I’m physically unattractive.”) were reverse-scored. Item responses were averaged to obtain a total score. Higher scores are indicative of greater body satisfaction. The MBSRQ-AE has demonstrated good internal consistency $(\alpha=.89)$ in another sample of female undergraduate students (Ata, Thompson, \& Small, 2013). Internal consistency of the MBSRQ-AE in the current sample was $\alpha=.89$.

Social desirability. Given the nature of the topic being studied, participants were asked to complete the Social Desirability Scale (SDS; Reynolds, 1982), a 13-item short form of the original 33-item Marlowe-Crowne Social Desirability Scale (MC-SDS; Crowne \& Marlowe, 
1960). Participants were asked to rate each of the statements (e.g., "I sometimes feel resentful when I don't get my way.") as true (1) or false (0). Higher scores represent a greater degree of socially desirable responding (i.e., participants attempted to portray themselves in a more favorable light). The 13-item SDS has demonstrated adequate 6-week test-retest reliability ( $\alpha=$ .74) and is highly correlated with the original version ( $r=.93$; Reynolds, 1982). In the current sample, $\alpha=.64$.

Disease and lifestyle informational articles. Two brief articles about obesity, similar in length and style, were written for the current study. The first article (word count: 203; FleschKincaid reading level: 10), defines overweight/obesity, provides prevalence estimates for the United States and world, and outlines lifestyle explanations for obesity (e.g., lack of physical activity, large portion sizes). The second article (word count: 199; Flesch-Kincaid reading level: 11) was based on the white paper written by the Council on the Obesity Society (Allison et al., 2008) and Kopelman and Finer's (2001) reply to an article arguing that obesity should not be considered a disease. This article, designed to serve as the intervention for the current study, notes the AMA's decision to designate obesity as a disease and the criteria used to make that determination. It also defines overweight/obesity; provides prevalence estimates for the United States and world, based on fact-sheets created by WHO (2013) and AHA (2013); and outlines biological/genetic explanations for obesity (e.g., thyroid malfunction).

Evaluation of articles. Participants were asked to rate the article they were assigned to read in terms of whether it was easy to read, useful, relevant, well-written, interesting, believable, and informative. Items were rated on a five-point Likert-type scale ranging from 
strongly disagree (1) to strongly agree (5). Participants were also asked to respond to three factual questions based on the article they just read (e.g., "Over the past 30 years, the number of people with obesity has [BLANK].”).

Distractor measures. To increase the study's credibility as an exploration of attitudes and beliefs about health/health-related behaviors and obscure its true purpose, participants were also asked to complete the following measures: the Pittsburgh Sleep Quality Index (PSQI; Buysse, Reynolds, Monk, Berman, \& Kupfer, 1989); the Mindfulness Attention Awareness Scale (MAAS; Brown \& Ryan, 2003); the Rapid Assessment of Physical Activity (RAPA; Topolski et al., 2006); the Drug Abuse Screen Test (DAST-10; Skinner, 1982); the Short Michigan Alcohol Screening Test (SMAST-13; Selzer, Vinokur, \& Van Rooijen, 1975) and the Centers for Disease Control and Prevention's Healthy Days core module (CDC HRQOL-4; CDC, 2000).

Demographics. Participants were encouraged to provide demographic information including race, ethnicity, age, year in school, height, weight, and perceived weight status ("very underweight", "slightly underweight", "healthy weight", "slightly overweight", "very overweight"; Lippa \& Sanderson, 2012). BMI ([weight in pounds/(height in inches $\left.\left.{ }^{2}\right)\right]$ x 703) was calculated using self-reported height in inches and weight in pounds.

Demand characteristics. To determine the potential influence of demand characteristics, a series of open-ended questions was used to assess participants' awareness of the true purpose of the study and related hypotheses. More specifically, participants were asked "What do you think the purpose of this study is?" and "What do you think the researcher's hypothesis is?" 
Attention checks. To ensure that participants fully attended to the questions, three items asking them to select a specific response (e.g., "Please choose definitely AGREE.") were randomly interspersed throughout the survey. Participants who did not correctly respond to at least two of these questions were removed from the data set prior to analyses.

Manipulation checks. Two items were added to the end of the survey to determine whether the manipulation had the desired effect of creating agreement with the lifestyle or disease view of the etiology of obesity (i.e., "Obesity is a lifestyle problem that results from poor food choices and lack of exercise." and "Obesity is a disease that results from genetic and biological factors."). Participants were instructed to rate their agreement with each item on a seven-point Likert-type scale ranging from strongly disagree (1) to strongly agree (7).

Additionally, participants were asked to respond to a single multiple choice item (i.e., "According to the article you read, obesity is a [BLANK]"). Response options, consistent with the two conditions to which participants could be assigned, included "disease" and "lifestyle choice."

Prior awareness of AMA decision. Participants were asked to respond to a yes/no question at the very end of the survey (i.e., "Did you know about the American Medical Association's decision to define obesity as a disease before participating in this study?").

\section{Procedure}

The study was advertised on SONA as an exploration of attitudes and beliefs about health and health-related behaviors (Diedrichs \& Barlow, 2011). Students who were eligible and 
interested signed up to attend an individual laboratory session. Upon entering the designated lab, participants were seated in front of a laptop. The primary investigator or a trained research assistant read the informed consent document out loud and answered participants' questions. Participants who agreed to participate were then asked to begin to complete the survey that was already open on the Desktop. They completed the pre-exposure ATOP and BAOP, MC-SDS, MBSRQ, and health-related distractor measures via an online survey hosted by Qualtrics.

Following completion of these measures, participants received a message asking them to "please let the research assistant know you have reached the first stop sign." At this point, each participant was randomly assigned, using a random number generator (www.random.org; Haahr, 2011), to the disease or lifestyle group. Participants were then provided a hardcopy of an article, purportedly being considered for inclusion in a university-based health magazine. Participants randomized to the lifestyle group were presented with an article about the lifestyle-related causes of obesity; participants randomized to the disease group received an article on the AMA's declaration of obesity as a disease and the genetic and biological causes of obesity. Participants were told they would be asked several questions about the article and should, therefore, read it carefully.

Having read the article, participants were asked to return to the online survey (still open on the computer) and rate the article in terms of whether it was easy to read, useful, relevant, well-written, interesting, believable, and informative. Having evaluated the article, participants completed the IAT task on the laptop using FreeIAT. Finally, participants returned to the survey to complete the post-exposure $\mathrm{BAOP}$ and ATOP and the manipulation check items. They were also asked to provide demographic information and answer a series of open-ended questions assessing their awareness of the actual purpose and hypotheses of the study. The final survey 
question asked participants whether they had heard of the AMA decision prior to participating in the study.

During debriefing, deception was revealed and participants were informed of the true purpose of the study. Prior to leaving, participants were asked to keep confidential the purpose of the study and thanked for their participation. 


\section{CHAPTER THREE:}

\section{RESULTS}

\section{Preliminary Analyses}

Missing data. Before subjected to analyses, data were screened for patterns of missing data. Missing values accounted for $<1 \%$ of the dataset. Two participants did not provide a selfreported weight, and one participant did not provide her height. Another participant was missing a single item on the pre-ATOP. A total of seven participants were missing IAT scores due to computer program error (i.e., they completed the task, but their data were not saved). Missing data for the IAT were imputed using the fully conditional specification maximum likelihood multiple imputation procedure in IBM SPSS statistical software. All study variables were included in the imputation model. The dataset including imputed values was used only for primary analyses where implicit weight bias was an outcome.

Discarded data. Next, data were screened for participants who did not correctly respond to a minimum of two attention check items. These participants were removed from the data set $(n$ =2). Data from participants who did not complete the outcome measure (i.e., post-exposure ATOP) and/or manipulation check item (e.g., due to computer or RA error) were also discarded $(n=2)$. This resulted in a final sample size of 146. 
Group equivalency checks. Full sample and group means, standard deviations, and frequencies were obtained (Table 1). To check for group equivalency, a series of independent samples t-tests was conducted on the continuous demographic variables. Groups did not exhibit significant differences in age $(t(144)=-0.35, p=.73)$, BMI $(t(142)=0.29, p=.77)$, body satisfaction (MBSRQ-AE; $t(144)=-0.24, p=.81)$, or social desirability $(\mathrm{SDS} ; t(144)=0.34, p=$ $.74)$.

Participants' evaluations of the articles (on usefulness, relevance, believability, etc.) were equivalent across groups $(t(144)=0.01, p=.99)$. The average rating, across groups and article characteristics, was 4.37 ( $S D=0.64$; where $5=$ "definitely agree"). To determine whether groups attended similarly to the content of the articles, responses to article-specific factual questions were recoded as incorrect (0) or correct (1), and a total score (out of 3) was calculated. Groups did not differ significantly on this score $(t(144)=0.70, p=0.49)$. The mean score, across groups, was $2.92(S D=0.28)$.

Chi-square tests were used to check for differences between groups on categorical demographic variables. The groups did not differ significantly in terms of race $\left(\chi^{2}(4)=3.16, p=\right.$ $.53)$, ethnicity $\left(\chi^{2}(1)=0.14, p=.71\right)$, year in school $\left(\chi^{2}(4)=8.93, p=.06\right)$, or perceived weight status $\left(\chi^{2}(3)=2.89, p=.41\right)$. Participants in both groups were equally aware of the AMA's decision to label obesity a disease $\left(\chi^{2}(1)=1.65, p=.20\right)$. Overall, $37 \%(n=54)$ of participants endorsed having been aware of the decision prior to participating in the study. The lack of significant differences between groups on the above variables provided assurance that the randomization procedure resulted in equal groups at baseline. 
Table 1

Participant Demographic Information

\begin{tabular}{|c|c|c|c|}
\hline & $\begin{array}{c}\text { Total } \\
(N=146)\end{array}$ & $\begin{array}{l}\text { Lifestyle } \\
(n=75)\end{array}$ & $\begin{array}{l}\text { Disease } \\
(n=71)\end{array}$ \\
\hline & $M(S D)$ & $M(S D)$ & $M(S D)$ \\
\hline Age & $19.84(4.82)$ & $19.71(3.48)$ & $19.99(5.94)$ \\
\hline \multirow[t]{2}{*}{ BMI } & $23.23(4.64)$ & $23.33(4.53)$ & $23.11(4.79)$ \\
\hline & $n(\%)$ & $n(\%)$ & $n(\%)$ \\
\hline \multicolumn{4}{|l|}{ Race } \\
\hline African American or Black & $29(19.9)$ & $15(20.0)$ & $14(19.7)$ \\
\hline Asian or Asian American & $11(7.5)$ & $8(8.0)$ & $5(7.0)$ \\
\hline White/Caucasian & $83(56.8)$ & $46(61.3)$ & $37(52.1)$ \\
\hline Multiracial & $8(5.5)$ & $3(4.0)$ & $5(7.0)$ \\
\hline Other & $15(10.3)$ & $5(6.7)$ & $10(14.1)$ \\
\hline \multicolumn{4}{|l|}{ Ethnicity } \\
\hline Hispanic/Latina & $37(25.3)$ & $20(26.7)$ & $17(23.9)$ \\
\hline \multicolumn{4}{|l|}{ Year in School } \\
\hline First & $82(56.2)$ & $38(50.7)$ & $44(62.0)$ \\
\hline Second & $28(19.2)$ & $15(20.0)$ & $13(18.3)$ \\
\hline Third & 17 (11.6) & $14(18.7)$ & $3(4.2)$ \\
\hline Fourth & $16(11.0)$ & $6(8.0)$ & $10(14.1)$ \\
\hline Other & $3(2.1)$ & $2(2.7)$ & $1(1.4)$ \\
\hline \multicolumn{4}{|l|}{ Weight Status ${ }^{\mathrm{a}}$} \\
\hline Underweight & $7(4.8)$ & $5(6.7)$ & $2(2.8)$ \\
\hline Normal weight & $107(73.3)$ & $49(65.3)$ & $58(81.7)$ \\
\hline Overweight & $18(12.3)$ & $13(17.3)$ & $5(7.0)$ \\
\hline Obese & $12(8.2)$ & $7(9.3)$ & $5(7.0)$ \\
\hline
\end{tabular}

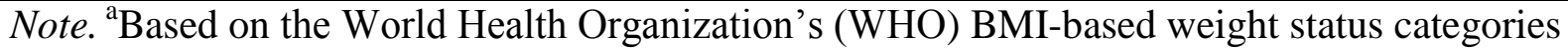
where Underweight $=\mathrm{BMI}<18.5$; Normal weight $=18.5 \geq \mathrm{BMI} \leq 24.9$; Overweight $=25 \geq$ $\mathrm{BMI} \leq 29.9$; Obese $=\mathrm{BMI} \geq 30$. 
Manipulation checks. Participants' responses on the two Likert-type manipulation check items (i.e., "Obesity is a lifestyle problem that results from poor food choices and lack of exercise." and "Obesity is a disease that results from genetic and biological factors.") differed significantly between groups. Participants in the lifestyle group $(M=5.96, S D=1.34)$ expressed significantly greater agreement with the lifestyle-consistent statement than participants in the disease group $(M=4.52, S D=1.90 ; t(144)=5.30, p<.001)$. Conversely, participants in the disease group $(M=6.06, S D=1.05)$ expressed significantly greater agreement with the statement defining obesity as a disease than participants in the lifestyle group $(M=5.17, S D=$ $1.37 ; t(144)=-4.35, p<.001)$. These two items indicate that the manipulation was effective; however, it should be noted that the mean differences were not large.

Participants also responded to a single categorical manipulation check item (i.e., "According to the article you read, obesity is a [BLANK]"). Response options included "disease" and "lifestyle choice." Of those participants randomized to the disease group, 94\% ( $n=$ $67)$ chose the disease option. However, only $63 \%(n=47)$ of participants in the lifestyle group chose the lifestyle option. Analyses were run with and without participants who did not choose the response option consistent with the group to which they were randomized. Of note, removal of participants from the dataset who did not "pass" this single item manipulation check resulted in unequal group sizes (lifestyle $n=47$; disease $n=67$ ). However, since results were comparable when analyses were run with and without participants who did not pass this manipulation check, only results for the full sample are reported. 


\section{Primary Analyses}

Explicit weight bias. To determine the effects of group and time on explicit weight bias (ATOP), a 2x2 mixed-model ANOVA was conducted. Time (two levels: pre- and post-exposure) was entered as the within-subjects factor and group (two levels: lifestyle, disease) was entered as the between-subjects factors. Although it was initially proposed as a covariate, SDS score was not included in the analysis, as it was not significantly correlated with explicit weight bias (Table 2). The main effects of time $\left(F(1,143)=0.06, p=.81\right.$, partial $\left.\eta^{2}=.00\right)$ and $\operatorname{group}(F(1,143)=$ $0.04, p=.85$, partial $\eta^{2}=.00$ ) on explicit weight bias were non-significant. Similarly, the interaction between time and group was non-significant $\left(F(1,143)=0.05, p=.83\right.$, partial $\eta^{2}=$ $.00)$. These results suggest explicit weight bias was similar across groups and time points.

Implicit weight bias. An independent samples t-test was conducted to determine the effect of group on implicit weight bias (IAT). There was no significant difference in IAT scores between the lifestyle $(M=-0.26, S D=0.30)$ and disease $(M=-0.25, S D=0.28)$ conditions $(t$ $(867)=-0.54, p=.59)$. Thus, the groups did not exhibit significant differences in implicit weight-biased attitudes post-exposure.

Beliefs about the controllability of weight. A 2(time) x 2(group) mixed-model ANOVA was conducted to determine the effects of time and group on beliefs about the controllability of weight $(\mathrm{BAOP})$. Results revealed a significant interaction between time and group, $F(1,144)=$ 4.41, $p<.05$, partial $\eta^{2}=.02$ (Figure 2). This suggests that the trajectory of beliefs about the controllability of weight was not the same between groups. 
Table 2

Correlations among Study Variables

\begin{tabular}{|c|c|c|c|c|c|c|c|c|}
\hline Measure & 1 & 2 & 3 & 4 & 5 & 6 & 7 & 8 \\
\hline 1. MBSRQ-AE & - & $.32 * *$ & $.33 * *$ & .05 & -.01 & -.01 & -.06 & $-.19 *$ \\
\hline 2. MBSRQ-FO & $.32 * *$ & - & $.64 * *$ & .04 & -.16 & $-.27 * *$ & -.14 & $-.20 *$ \\
\hline 3. MBSRQ-HO & $.33 * *$ & $.64 * *$ & - & .03 & -.03 & -.15 & -.09 & -.07 \\
\hline 4. SDS & .05 & .04 & .03 & - & $.20 *$ & .15 & .12 & .01 \\
\hline 5. ATOP $^{\mathrm{a}}$ & -.00 & $-.21 *$ & -.08 & .14 & - & $.41 * *$ & .07 & $.21^{*}$ \\
\hline 6. $\mathrm{BAOP}^{\mathrm{a}}$ & -.03 & $-.24 * *$ & -.13 & .15 & $.51 * *$ & - & .11 & .12 \\
\hline 7. Overall IAT score & -.06 & -.14 & -.09 & .12 & $.17 *$ & .10 & - & -.07 \\
\hline 8. BMI & $-.19 *$ & $-.20 *$ & -.07 & .01 & $.18^{*}$ & .08 & -.07 & - \\
\hline
\end{tabular}

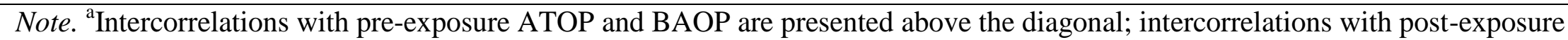
ATOP and BAOP are presented below the diagonal. Pre- and post-exposure ATOP $(r=.74)$ and BAOP $(r=.71)$ scores were highly correlated $(p$ 's <.001). MBSRQ-AE = Multidimensional Body-Self Relations Questionnaire- Appearance Evaluation subscale; MBSRQ-FO = Multidimensional Body-Self Relations Questionnaire- Fitness Orientation subscale; Multidimensional Body-Self Relations Questionnaire- Health Orientation subscale; SDS = Social Desirability Scale- Short Form; ATOP = Attitudes toward Obese Persons; BAOP = Beliefs about Obese Persons; IAT = Implicit Association Task; BMI = body mass index.

$* p<.05, * * p<.01, * * * p<.001$. 


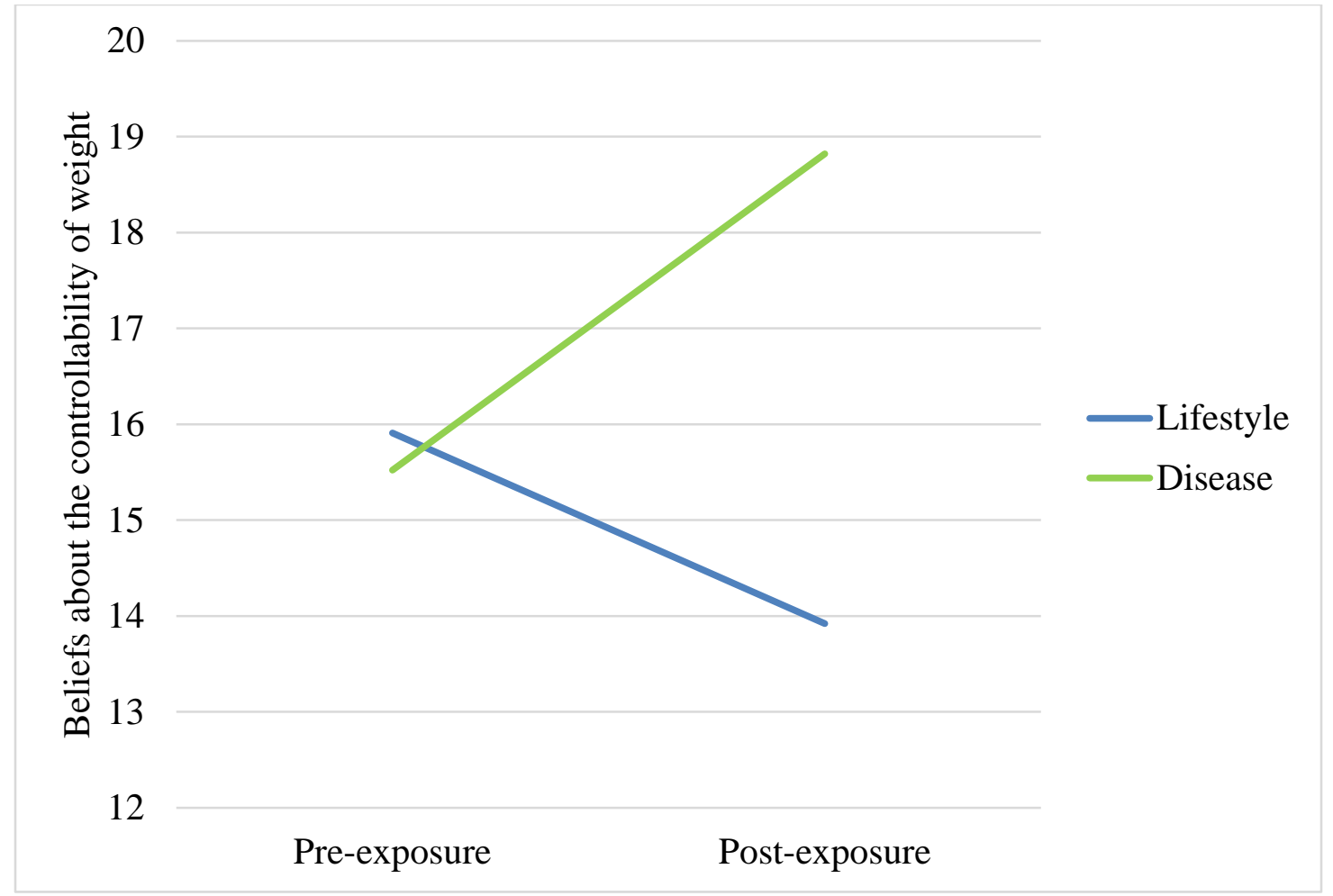

Figure 2. Effects of time and group on beliefs about the controllability of weight 
Participants who read the article defining obesity as a disease expressed a significant increase in BAOP scores from pre- to post-exposure, indicating a strengthening of the belief that obesity is not under a person's control. Participants who read the article defining obesity as a lifestyle problem exhibited a significant decrease in BAOP scores from pre- to post-exposure, indicating a weakening of the belief that obesity is not under a person's control (see Table 3 for means and standard deviations).

\section{Mediation Analysis}

The PROCESS procedure for IBM SPSS statistical software, which employs the bootstrapping method (Hayes, 2012; Preacher \& Hayes, 2008), was used to determine whether the relationship between group and post-exposure explicit weight-biased attitudes was mediated by pre-to-post change in beliefs about the controllability of weight (Figure 1). Pre-exposure ATOP score was entered as a covariate. One of the primary strengths of the bootstrapping technique is that it does not assume normality of the sampling distribution of indirect effects, an assumption that is frequently violated in smaller samples (Hayes, 2009; Preacher \& Hayes, 2004, 2008). Further, simulation studies suggest that bootstrapping is more powerful than the Sobel Test and Baron and Kenny's (1986) causal steps approach to mediation (Hayes, 2009; Preacher \& Hayes, 2004, 2008). Results for the indirect effect, based on 5000 samples drawn randomly with replacement from the dataset, were indicative of non-significant mediation, as the biascorrected $95 \%$ confidence interval $(\mathrm{CI})$ contained zero $(95 \% \mathrm{CI}=[-2.68,2.09])$. Both the direct effect of group on post-exposure explicit weight bias, and the indirect effect of group on postexposure explicit weight bias via change in beliefs about the controllability of weight, were nonsignificant (Figure 3). 
Table 3

Means and Standard Deviations

\begin{tabular}{|c|c|c|c|c|}
\hline Measure & $\begin{array}{c}\text { Total } \\
(N=146)\end{array}$ & $\begin{array}{l}\text { Lifestyle } \\
(n=75)\end{array}$ & $\begin{array}{l}\text { Disease } \\
(n=71)\end{array}$ & $t$ \\
\hline MBSRQ-AE & $3.46(0.76)$ & $3.44(0.77)$ & $3.47(0.76)$ & -0.24 \\
\hline MBSRQ-FO & $3.42(0.85)$ & $3.31(0.81)$ & $3.53(0.88)$ & -1.56 \\
\hline MBSRQ-HO & $3.55(0.66)$ & $3.47(0.64)$ & $3.64(0.66)$ & -1.60 \\
\hline SDS & $7.55(2.65)$ & $7.63(2.82)$ & $7.48(2.48)$ & 0.34 \\
\hline \multicolumn{5}{|l|}{ ATOP } \\
\hline Pre & $65.14(18.39)$ & $65.28(19.53)$ & $65.00(17.24)$ & 0.10 \\
\hline Post & $64.93(17.15)$ & $65.25(15.72)$ & $64.59(18.66)$ & 0.23 \\
\hline \multicolumn{5}{|l|}{ BAOP } \\
\hline Pre & $15.72(6.77)$ & $15.91(6.41)$ & $15.52(7.17)$ & 0.34 \\
\hline Post & $16.30(7.42)$ & $13.92(5.87)$ & $18.82(8.06)$ & $-4.21 * * *$ \\
\hline Change (post - pre) & $0.58(5.41)$ & $-1.99(4.19)$ & $3.30(5.25)$ & $-6.74 * * *$ \\
\hline Overall IAT score & $-0.25(0.29)$ & $-0.26(0.31)$ & $-0.25(0.28)$ & -0.11 \\
\hline
\end{tabular}

Note. MBSRQ-AE = Multidimensional Body-Self Relations Questionnaire- Appearance Evaluation subscale; MBSRQ-FO = Multidimensional Body-Self Relations QuestionnaireFitness Orientation subscale; Multidimensional Body-Self Relations Questionnaire- Health Orientation subscale; SDS = Social Desirability Scale- Short Form; ATOP = Attitudes toward Obese Persons; BAOP = Beliefs about Obese Persons; IAT = Implicit Association Task. $t=$ results for independent samples t-tests comparing lifestyle vs. disease group means.

$* p<.05, * * p<.01, * * * p<.001$. 


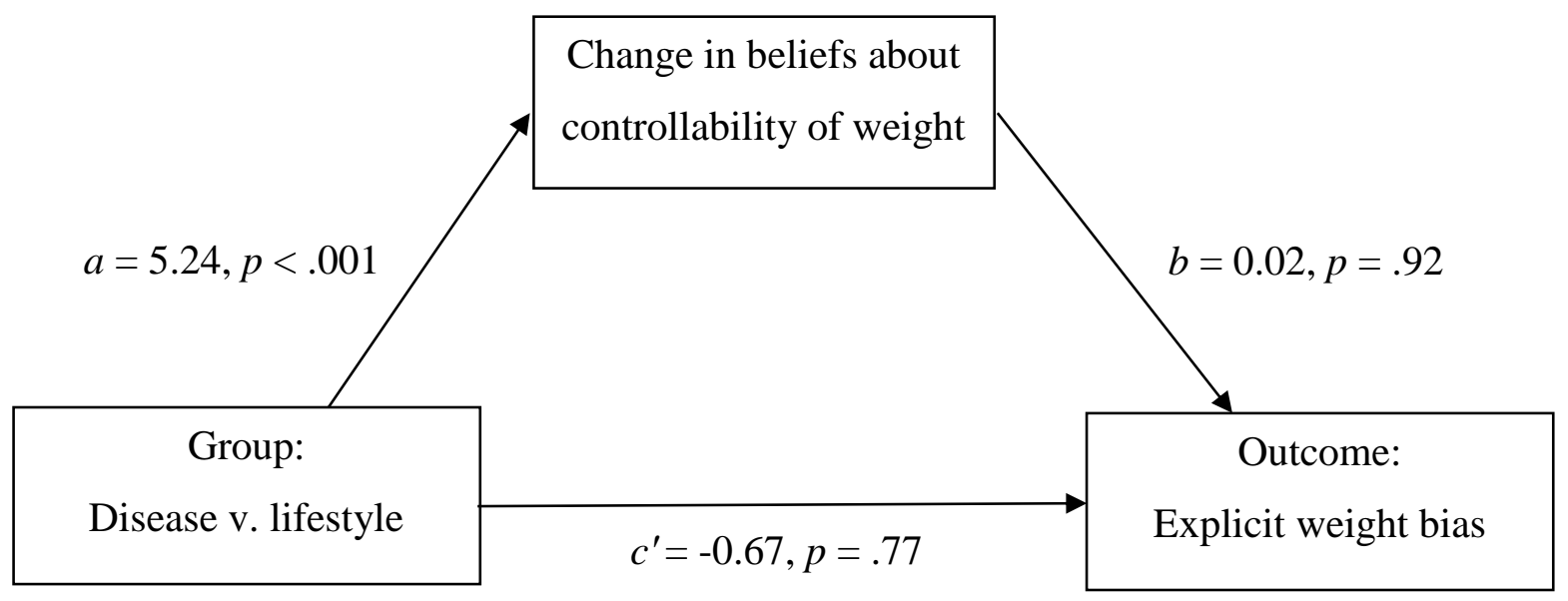

Figure 3. Change in beliefs about the controllability of weight as a mediator of the relationship between group and explicit weight-biased attitudes (with pre-exposure ATOP score as a covariate). 


\section{Moderation Analyses}

Moderation analyses were run via the PROCESS procedure for IBM SPSS statistical software (Hayes, 2012) to determine whether the relationship between group and post-exposure explicit weight-biased attitudes was moderated by fitness orientation (MBSRQ-FO), health orientation (MBSRQ-HO), or BMI. A separate analysis was conducted for each moderator; preexposure ATOP score was entered as a covariate in all analyses. For fitness orientation, results indicated a significant overall model, $R^{2}=0.56, F(4,140)=44.10, p<.001$. The interaction between fitness orientation and group, however, was non-significant $(B=-1.85, p=.43)$. The increase in $R^{2}$ due to the interaction was less than 0.01 . Similar results were obtained for health orientation. The overall model $\left(R^{2}=0.56, F(4,140)=43.83, p<.001\right)$, but not the interaction between health orientation and group $(B=-3.87, p=.20)$, was significant. Change in $R^{2}$ due to the interaction was less than 0.01. For BMI, results suggested a significant overall model, $R^{2}=$ $0.55, F(4,138)=42.63, p<.001$. The interaction between BMI and group was non-significant $(B=0.26, p=0.55)$, and its inclusion in the model resulted in an $R^{2}$ change of less than 0.01 . Neither fitness orientation, health orientation, nor BMI were found to be significant moderators of the relationship between group and post-exposure explicit weight bias. 


\section{CHAPTER FOUR:}

\section{DISCUSSION}

The current study sought to determine whether presenting obesity as a disease would affect implicit or explicit weight-biased attitudes and/or weight-biased beliefs in undergraduate females who were randomly assigned to read an article defining obesity as a disease attributable to genetic and biological factors versus an article describing obesity as the result of poor lifestyle choices. In addition, pre- to post-exposure change in beliefs about controllability of weight was examined as a potential mediator of the relationship between group and explicit weight-biased attitudes. BMI, fitness orientation, and health orientation were examined as potential moderators of this relationship.

It was hypothesized that labeling obesity as a disease caused by genetic and biological factors would reduce explicit weight-biased attitudes. Results did not support this hypothesis. Main effects for group and time, as well at the interaction between the two variables, were nonsignificant. Given that approximately $40 \%$ of participants did not pass the manipulation check (i.e., respond in a manner consistent with the group to which they were randomized), it is unclear whether the non-significant findings are attributable to lack of effect or weak manipulation. The fact that results remained non-significant when the analyses were re-run including only those participants who passed the manipulation check may have been due to insufficient power (revised $n=114$ ). Meta-analytic results support a small to medium effect of weight bias reduction interventions on weight-biased attitudes (Hedges' $g=-0.33, p<.001$; Lee et al., 2014). 
Although moderator analyses indicated a non-significant effect of intervention type, on average, the effect size for controllability interventions (Hedges' $g=-0.21$ ) is lower than the effect size for other intervention types (Lee et al., 2014). Since the current study falls within the controllability category, basing the power analysis on a small effect size would have increased the likelihood of obtaining a significant effect.

While inadequate power may explain the lack of significant group effect, it does not provide a rationale for the skewed manipulation check results between groups. Participants who were randomly assigned to read the article framing obesity as the result of poor lifestyle choices were almost equally likely to report that the article they read described obesity as a disease (37\%) versus lifestyle choice (63\%). Interestingly, this response pattern was not observed in the disease condition, where almost all (94\%) of the participants chose the correct response. It is possible that a participant's tendency to choose "disease," regardless of the group to which she was assigned, is related to expectancies. The concept of expectancy, first applied to general learning theory in 1932, has since been generalized to diverse areas of scientific inquiry (Goldman, Darkes, Reich, \& Brandon, 2006). At the most basic level, participants' expectancies may have caused them to overlook the specific text of the item and respond in a manner consistent with pre-existing beliefs. Although only $32 \%$ of participants in the lifestyle group expressed awareness of the AMA's decision to designate obesity a disease, they may have been inadvertently affected by exposure to news articles and debates on the topic.

It was further hypothesized that change in beliefs about the controllability of weight would mediate the relationship between group and post-exposure explicit weight-biased attitudes. This hypothesis was not supported by the data. Although post-exposure beliefs about the controllability of weight differed significantly across groups, with participants in the disease 
group increasing from pre to post and participants in the lifestyle group decreasing over the same time period, results of the mediation analysis were not significant. These results are consistent with meta-analytic results indicating a small, positive effect of weight-bias interventions on weight-biased beliefs (Lee et al., 2014) and suggest that defining obesity as a disease increased participants' beliefs that obesity is not under a person's direct control. The change in beliefs, however, did not extend to weight-biased attitudes. Thus, results are inconsistent with Attribution Theory (Heider, 1958), which suggests that the more people believe weight is attributable to factors within an individual's control, the stronger the weight-biased attitudes they will express.

Finally, it was predicted that BMI, fitness orientation, and health orientation would moderate the relationship between group and explicit weight-biased attitudes. Results from the moderation analyses were non-significant. The inability to detect significant moderation may be attributable to insufficient power. Although an associated hypothesis was not generated, the effect of group on implicit weight-biased attitudes was also examined. Results suggested that defining obesity as a disease versus the result of lifestyle choices did not have an effect on implicit weight-biased attitudes, as measured by the IAT. These results are not surprising, given that implicit attitudes are more resistant to change than explicit attitudes (Gawronski \& Bodenhausen, 2006; Rydell \& McConnell, 2006) and may require a multi-strategy intervention (e.g., Rukavina et al., 2010).

Research conducted since the proposal of the current study suggests there are "hidden costs associated with labeling obesity as a disease" (Hoyt, Burnette, \& Auster-Gussman, 2014, p. 997). In one of three studies, Hoyt and colleagues (2014) randomly assigned participants to read a New York Times article about the AMA's decision to categorize obesity as a disease or a 
"control" article on why obesity is not a disease. Results indicated that, for participants with obesity, decreased body dissatisfaction significantly mediated the relationship between exposure to the disease message and less healthful food choice (i.e., choosing a higher calorie sandwich when presented with a menu of options varying in caloric content from 230 - 980 calories).

\section{Limitations and Future Directions}

Although the current study is, to the researcher's knowledge, the first to experimentally examine the effect of defining obesity as a disease on weight-biased attitudes and beliefs, the findings should be considered in the context of several limitations. First, given the nature of the sample (i.e., female undergraduates), the generalizability of the results is limited. Participation in the current study was restricted to females due to recruitment difficulties; however, evidence suggests that both males and females are subjected to and demonstrate weight-bias (Latner, O’Brien, Durso, Brinkman, \& MacDonald, 2008; Latner, Stunkard, \& Wilson, 2005; Puhl \& Heuer, 2009). Thus, future research should seek to examine the effect of the AMA's decision to designate obesity as a disease in a coed sample that would allow for gender-based comparisons. It may also be interesting to determine how individuals across the lifespan differ in their reactions to the decision and its effects on their views about people with obesity and weight management behaviors. Results from a large, online survey of adults $(n=48,235)$ and healthcare professionals $(n=3,828)$ in the U.S. suggest that older respondents are more likely to view obesity as a medical problem than their younger counterparts (Kyle, Thomas, \& Tsai, 2014).

Second, the current study utilized a free computer program (i.e., FreeIAT) to measure implicit weight-biased attitudes. For the purposes of the study, the program was customized to include images of male and female faces edited to appear "thin" or "fat" obtained from the "For 
Researchers" section of the Project Implicit website (https://www.projectimplicit.net/stimuli.html). Although the images were black-and-white, the race/ethnicity of the individuals was discernable and, therefore, a potential confounding variable. Future studies seeking to examine implicit weight-biased attitudes should employ more current versions of the weight-related IAT, such as the one hosted by Project Implicit, which utilize body silhouettes as opposed to images of faces. Additionally, IAT scores for several participants $(n=$ 7) had to be imputed prior to analyses due to program and research assistant errors that resulted in data not being saved. For-purchase IAT software (e.g., Inquisit by Millisecond; WwW.millisecond.com), which can be embedded directly into online surveys, may further reduce the potential for human error. Researchers may also consider incorporating an IAT developed to measure implicit self-discrimination (SD-IAT; Rudolph \& Hilbert, 2015) into future studies in this area.

Third, the design of the study unintentionally implies that the contributions of genetic/biological factors and lifestyle choices to obesity are mutually exclusive. Whether obesity is a disease does not negate the importance of lifestyle choices in successful weight management. Many diseases, such as cardiovascular disease, cancer, and type II diabetes, can be positively or negatively impacted by individual behavior. Indeed, there is strong support for an association between modifiable risk factors (e.g., substance use, physical inactivity, unhealthful diet) and increasing rates of chronic diseases (e.g., Danaei et al., 2009; Leventhal, Huh, \& Dunton, 2014). Participants' responses to items designed to assess belief that "obesity is a lifestyle problem that results from poor food choices and lack of exercise" versus "obesity is a disease that results from genetic and biological factors" suggest comparable agreement with both statements [lifestyle $M=5.26$, disease $M=5.60$; response options ranged from strongly disagree 
(1) to strongly agree (7)]. It would be interesting to determine whether responses would differ across groups asked to assign relative percentages $(0-100 \%)$ of weight caused by biological/genetic versus lifestyle factors (e.g., Persky \& Eccleston, 2011).

\section{Conclusions and Implications}

Despite its limitations, this experiment makes a timely contribution to the debate stemming from the AMA's decision to designate obesity a disease. Results suggest that conceptualizing obesity as the result of biology and genes had a significant effect on weightbiased beliefs, but not explicit or implicit weight-biased attitudes. Although only time will reveal the natural consequences of the AMA's decision to designate obesity a disease, mere awareness appears to be insufficient to elicit change in attitudes - particularly implicit attitudes, which are more resistant to change. Obesity is a complex and multi-determined condition; the most effective public health messages may be those that recognize factors both within and outside of a

person's control, thereby simultaneously reducing weight-related stigma and promoting healthful weight-control behaviors. 


\section{REFERENCES}

Allison, D. B., Basile, V. C., \& Yuker, H. E. (1991). The measurement of attitudes toward and beliefs about obese persons. International Journal of Eating Disorders, 10, 599 - 607.

Allison, D. B., Downey, M., Atkinson, R. L., Billington, C. J., Bray, G. A., Eckel, R.

H.,...Tremblay, A. (2008). Obesity as a disease: A white paper on evidence and arguments commissioned by the Council of The Obesity Society. Obesity, 16, $1161-$ 1177. doi:_10.1038/oby.2008.231

American Heart Association (AHA; 2013, March). With a very heavy heart: Obesity and cardiovascular disease (CVD). Retrieved from: http://www.heart.org/policyfactsheets

Amy, N. K., Aalborg, A., Lyons, P., \& Keranen, L. (2006). Barriers to routine gynecological cancer screening for White and African-American obese women. International Journal of Obesity, 30, 147 - 155. doi: 10.1038/sj.ijo.0803105

Andreyeva, T., Puhl, R. M., \& Brownell, K. D. (2008). Changes in perceived weight discrimination among Americans, 1995-1996 through 2004-2006. Obesity, 16, 1129 1134. doi: 10.1038/oby.2008.35

Annis, N. M., Cash, T. F., Hrabosky, J. I. (2004). Body image and psychosocial differences among stable average weight, currently overweight, and formerly overweight women: The role of stigmatizing experiences. Body Image: An International Journal of Research, 1, 155 - 167. doi: http://dx.doi.org.ezproxy.lib.usf.edu/10.1016/j.bodyim.2003.12.001. 
Ata, R. N., Thompson, J. K., \& Small, B. J. (2013). Effects of exposure to thin-ideal media images on body dissatisfaction: Testing the inclusion of a disclaimer versus warning label. Body Image: An International Journal of Research, 10, 472 - 480. doi: http://dx.doi.org.ezproxy.lib.usf.edu/10.1016/j.bodyim.2013.04.004.

Baron, R. M., \& Kenny, D. A. (1986). The moderator-mediator variable distinction in social psychological research: Conceptual, strategic, and statistical considerations. Journal of Personality and Social Psychology, 51, 1173 - 1182. doi: http://dx.doi.org.ezproxy.lib.usf.edu/10.1037/0022-3514.51.6.1173 .

Brown, K. W., \& Ryan, R. M. (2003). The benefits of being present: Mindfulness and its role in psychological well-being. Journal of Personality and Social Psychology, 84, 822 - 848. doi: $10.1037 / 0022-3514.84 .4 .822$

Brown, T. A., Cash, T. F., \& Mikulka, P. J. (1990). Attitudinal body-image assessment: Factor analysis of the Body-Self Relations Questionnaire. Journal of Personality Assessment, 55, 135 - 144. doi: 10.1207/s15327752jpa5501\&2_13

Brownell, K. D. (2005). Introduction: The social, scientific, and human context of prejudice and discrimination based on weight. In K. D. Brownell, R. M. Puhl, M. B. Schwartz, \& L. Rudd (Eds.), Weight bias: Nature, consequences, and remedies (pp. 1-11). New York, NY, US: The Guilford Press.

Buysse, D. J., Reynolds III, C. F., Monk, T. H., Berman, S. R., \& Kupfer, D. J. (1989). The Pittsburgh sleep quality index: A new instrument for psychiatric practice and research. Psychiatry Research, 28, 193 - 213. doi: 10.1016/0165-1781(89)90047-4

Cahnman, W. J. (1968). The stigma of obesity. The Sociological Quarterly, 9, 283 - 299. 
Campbell, M. C., \& Mohr, G. S. (2011). Seeing is eating: How and when activation of a negative stereotype increases stereotype-conducive behavior. Journal of Consumer Research, 38, 431 - 444. doi: 10.1086/659754

Centers for Disease Control and Prevention (CDC; 2000). Measuring healthy days: Population assessment of health-related quality of life. Atlanta, GA, US: CDC.

Chen, E. Y., \& Brown, M. (2005). Obesity stigma in sexual relationships. Obesity Research, 13, 1393 -1397. doi: 10.1038/oby.2005.168

Ciao, A. C., \& Latner, J. D. (2011). Reducing obesity stigma: The effectiveness of cognitive dissonance and social consensus interventions. Obesity, 19, 1768 - 1774. doi: http://dx.doi.org.ezproxy.lib.usf.edu/10.1038/oby.2011.106 .

Crandall, C. (1994). Prejudice against fat people: Ideology and self-interest. Journal of Personality and Social Psychology, 66, 882 - 894. doi: 10.1037/0022-3514.66.5.882

Crandall, C. S., D’Anello, S., Sakalli, N., Lazarus, E., Nejtardt, G. W., \& Feather, N. T. (2001). An attribution-value model of prejudice: Anti-fat attitudes in six nations. Personality and Social Psychology Bulletin, 27, 30 - 37. doi: 10.1177/0146167201271003

Crandall, C. S., \& Reser, A. H. (2005). Attributions and weight-based prejudice. In K. D. Brownell, R. M. Puhl, M. B. Schwartz, \& L. Rudd (Eds.), Weight bias: Nature, consequences, and remedies (pp. 83 -96). New York: The Guilford Press.

Crowne, D. P., \& Marlowe, D. (1960). A new scale of social desirability independent of psychopathology. Journal of Consulting Psychology, 24, 349-354. doi:

$10.1037 / \mathrm{h} 0047358$ 
Cunningham, W. A., Preacher, K. J., \& Banaji, M. R. (2001). Implicit attitude measures: Consistency, stability, and convergent validity. Psychological Science, 12, $163-170$. doi: $10.1111 / 1467-9280.00328$

Danaei, G., Ding, E. L., Mozaffarian, D., Taylor, B., Rehm, J., Murray, C. J., \& Ezzati, M. (2009). The preventable causes of death in the United States: Comparative risk assessment of dietary, lifestyle, and metabolic risk factors. PLoS Medicine, 6, e1000058. doi: 10.1371/journal.pmed.1000058

Daníelsdóttir, S., O’Brien, K., \& Ciao, A. (2010). Anti-fat prejudice reduction: A review of published studies. Obesity Facts, 3, 47 - 58. doi: 10.1159/000277067

DeJong, W. (1980). The stigma of obesity: The consequences of naïve assumptions concerning the causes of physical deviance. Journal of Health and Social Behavior, 21, 75 - 87. doi: $10.2307 / 2136696$

Diedrichs, P. C., \& Barlow, F. K. (2011). How to lose weight bias fast! Evaluating a brief antiweight bias intervention. British Journal of Health Psychology, 16, 846-861. doi:10.1111/j.2044-8287.2011.02022.x

Ebneter, D. S., Latner, J. D., \& O’Brien, K. S. (2011). Just world beliefs, causal beliefs, and acquaintance: Associations with stigma toward eating disorders and obesity. Personality and Individual Differences, 51, 618 - 622. doi: 10.1016/j.paid.2011.05.029

Eisenberg, M. E., Neumark-Sztainer, D., Haines, J., \& Wall, M. (2006). Weight-teasing and emotional well-being in adolescents: Longitudinal findings from Project EAT. Journal of Adolescent Health, 38, 675 - 683. doi:

http://dx.doi.org.ezproxy.lib.usf.edu/10.1016/j.jadohealth.2005.07.002 . 
Finkelstein, E. A., Khavjou, O. A., Thompson, H., Trogdon, J. G., Pan, L., Sherry, B., \& Dietz, W. (2012). Obesity and severe obesity forecasts through 2030. American Journal of Preventative Medicine, 42, 563 - 570. doi: 10.1016/j.amepre.2011.10.026

Fischer, R., Collet, T. H., Zeller, A., Zimmerli, L., Gaspoz, J. M., Giraudon, K., ..., \& Cornuz, J. (2013). Obesity and overweight associated with lower rates of colorectal cancer screening in Switzerland. European Journal of Cancer Prevention.

Friedman, A. M., Hemler, J. R., Rossetti, E., Clemow, L. P., \& Ferrante, J. M. (2012). Obese women's barriers to mammography and Pap smear: The possible role of personality. Obesity, 20, 1611 - 1617. doi: 10.1038/oby.2012.50

Gapinski, K. D., Schwartz, M. B., \& Brownell, K. D. (2006). Can television change anti-fat attitudes and behavior? Journal of Applied Biobehavioral Research, 11, 1 - 28. doi: 10.1111/j.1751-9861.2006.tb00017.x

Garrey, S. (2013, June 21). Calling obesity a disease: Fat acceptance advocates predict more stigma. Common Health. Retrieved from http://commonhealth.wbur.org/2013/06/obesityama-fat-acceptance

Gawronski, B., \& Bodenhausen, G. V. (2006). Associative and propositional processes in evaluation: An integrative review of implicit and explicit attitude change. Psychological Bulletin, 132, 692 - 731. doi: 10.1037/0033-2909.132.5.692

Goldman, M. S., Darkes, J., Reich, R. R., \& Brandon, K. O. (2006). From DNA to conscious thought: The influence of anticipatory processes on human alcohol consumption. In M. Munafò, \& I. Albery (Eds.), Cognition and addiction (pp. 147 - 184). New York: Oxford University Press. 
Greenwald, A. G., \& Banaji, M. R. (1995). Implicit social cognition: Attitudes, self-esteem, and stereotypes. Psychological Review, 102, 4 - 27. doi: 10.1037/0033-295X.102.1.4

Greenwald, A. G., McGhee, D. E., \& Schwartz, J. L. K. (1998). Measuring individual differences in implicit cognition: The Implicit Association Test. Journal of Personality and Social Psychology, 74, 1464 - 1480. doi: 10.1037/0022-3514.74.6.1464

Greenwald, A. G., \& Nosek, B. A. (2001). Health of the Implicit Association Test at age 3. Zietschrift fur Experimentelle Psychologie, 48, 85 - 93. doi: 10.1026//0949-3946.48.2.85

Greenwald, A. G., Nosek, B. A., \& Banaji, M. R. (2003). Understanding and using the implicit association test: I. An improved scoring algorithm. Journal of Personality and Social Psychology, 85, 197-216.

Grover, V. P., Keel, P. K., \& Mitchell, J. P. (2003). Gender differences in implicit weight identity. International Journal of Eating Disorders, 34, 125 - 135. doi: 10.1002/eat.10167

Gumble, A., \& Carels, R. (2012). The harmful and beneficial impacts of weight bias on wellbeing: The moderating influence of weight status. Body Image: An International Journal of Research, 9, 101 - 107. doi: http://dx.doi.org.ezproxy.lib.usf.edu/10.1016/j.bodyim.2011.07.005 .

Haahr, M. (2011). True random number generator. Retrieved from http://www.random.org Hague, A. L., \& White, A. A. (2005). Web-based intervention for changing attitudes of obesity among current and future teachers. Journal of Nutrition Education and Behavior, 37, 58 66. doi: 10.1016/S1499-4046(06)60017-1 
Haines, J., \& Neumark-Sztainer, D. (2009). Psychosocial consequences of obesity and weight bias: Implications for interventions. In L. J. Heinberg \& J. K. Thompson (Eds.), Obesity in youth: Causes, consequences, and cures (pp. 79 -98). Washington, DC, US:

American Psychological Association.

Hayes, A. F. (2009). Beyond Baron and Kenny: Statistical Mediation Analysis in the New Millenium. Communication Monographs, 76, 408 - 420. doi:

$10.1080 / 03637750903310360$

Hayes, A. F. (2012). PROCESS: A versatile computational tool for observed variable mediation, moderation, and conditional process modeling [White paper]. Retrieved from http://www.afhayes.com/public/process2012.pdf

Hebl, M. R., Ruggs, E. N., Singletary, S. L., \& Beal, D. J. (2008). Perceptions of obesity across the lifespan. Obesity, 16, S46 - S52. doi: 10.1038/oby.2008.458

Hebl, M. R., \& Xu, J. (2001). Weighing the care: Physicians'reactions to the size of a patient. International Journal of Obesity, 25, 1246 - 1252. doi: 10.1038/sj.ijo.0801681

Heider, F. (1958). The psychology of interpersonal relationships. New York, NY, US: Wiley.

Henderson, K. E., \& Brownell, K. D. (2004). The toxic environment and obesity: Contribution and cure. In J. K. Thompson (Ed.), Handbook of Eating Disorders and Obesity (pp. 349 371). Hoboken, NJ, US: Wiley.

Hoyt, C. L., Burnette, J. L., \& Auster-Gussman, L. (2014). "Obesity is a disease": Examining the self-regulatory impact of this public-health message. Psychological Science, 25, 997 1002. doi: $10.1177 / 0956797613516981$

Katz, D. (2014). Health: The medicalization of fat. Nature, 510, 34. doi: 10.1038/510034a 
Kopelman, P. G., \& Finer, N. (2001). Reply: Is obesity a disease? International Journal of Obesity, 25, $1405-1406$.

Kyle, T., Thomas, D., \& Tsai, A. (2014, November). Obesity is increasingly viewed as a community problem by both the public and healthcare professionals. Poster presented at The Obesity Society Annual Meeting, Boston, MA.

Latner, J. D., O’Brien, K. S., Durso, L. E., Brinkman, L. A., \& MacDonald, T. (2008). Weighing obesity stigma: The relative strength of different forms of bias. International Journal of Obesity, 32, 1145 - 1152. doi: 10.1038/ijo.2008.53

Latner, J. D., Stunkard, A. J., \& Wilson, G. T. (2005). Stigmatized students: Age, sex, and ethnicity effects in the stigmatization of obesity. Obesity, 13, 1226-1231. doi: 10.1038/oby.2005.145

Lee, M., Ata, R. N., \& Brannick, M. T. (2014). Malleability of weight-biased attitudes and beliefs: A meta-analysis of weight bias reduction interventions. Body Image: An International Journal of Research, 11, $251-259$. http://dx.doi.org.ezproxy.lib.usf.edu/10.1016/j.bodyim.2014.03.003

Leventhal, A. M., Huh, J., \& Dunton, G. F. (2014). Clustering of modifiable biobehavioral risk factors for chronic disease in US adults: A latent class analysis. Perspectives in Public Health, 134, 331 - 338. doi: 10.1177/1757913913495780

Lewis, R. J., Cash, T. F., \& Bubb-Lewis, C. (1997). Prejudice toward fat people: The development and validation of the Antifat Attitudes Test. Obesity Research, 5, 297-307.

Lippa, N.C., \& Sanderson, S.C. (2012). Impact of information about obesity genomics on the stigmatization of overweight individuals: An experimental study. Obesity, 20, 2367-2376. doi:10.1038/oby.2012.144 
McClure, K. J., Puhl, R. M., \& Heuer, C. A. (2011). Obesity in the news: Do photographic images of obese persons influence antifat attitudes?. Journal of Health Communication, 16, 359 - 371. doi: 10.1080/10810730.2010.535108

Meade, A. W. (2009). FreeIAT: An open-source program to administer the implicit association test. Applied Psychological Measurement, 33, 643.

Menzel, J. E., Schaefer, L. M., Burke, N. L., Mayhew, L. L., Brannick, M. T., \& Thompson, J. K. (2010). Appearance-related teasing, body dissatisfaction, and disordered eating: A meta-analysis. Body Image, 7, 261 - 270. doi: 10.1016/j.bodyim.2010.05.004

Miller Jr., D. P., Spangler, J. G., Vitolins, M. Z., Davis, S. W., Ip, E. H., Marion, G. S., \& Crandall, S. J. (2013). Are medical students aware of their anti-obesity bias? Academic Medicine, 88, $978-982$.

Must, A., Spadano, J., Coakley, E. H., Field, A. E., Colditz, G., \& Dietz, W. H. (1999). The disease burden associated with overweight and obesity. Journal of the American Medical Association, 282, 1523 - 1529.

Neumark-Sztainer, D., Wall, M., Haines, J., Story, M., Sherwood, N. E., \& van den Berg, P. A. (2007). Shared risk and protective factors for overweight and disordered eating in adolescents. American Journal of Preventive Medicine, 33, 359 - 369. doi: 10.1016/j.amepre.2007.07.031

Neumark-Sztainer, D., Wall, M., Story, M., \& Sherwood, N. E. (2009). Five-year longitudinal predictive factors for disordered eating in a population-based sample of overweight adolescents: Implications for prevention and treatment. International Journal of Eating Disorders, 42, 664 - 672. doi: 10.1002/eat.20733 
Nosek, B. A., Greenwald, A. G., \& Banaji, M. R. (2007). The Implicit Association Test at age 7: A methodological and conceptual review. In J. A. Bargh (Ed.), Automatic processes in social thinking and behavior (pp. 265 - 292). New York, NY, US: Psychology Press.

Nosek, B. A., Smyth, F. L., Hansen, J. J., Devos, T., Lindner, N. M., Ranganath, K. A., ... Banaji, M. R. (2007). Pervasiveness and correlates of implicit attitudes and stereotypes. European Review of Social Psychology, 18, $36-88$.

Ogden, C. L., Carroll, M. D., Kit, B. K., \& Flegal, K. M. (2012). Prevalence of obesity in the United States, 2009-2010. NCHS Data Brief, 82. Retrieved from http://www.cdc.gov/nchs/data/databriefs/db82.pdf

Persky, S., \& Eccleston, C. P. (2011). Impact of genetic causal information on medical students' clinical encounters with an obese virtual patient: Health promotion and social stigma. Annals of Behavioral Medicine, 41, 363 - 372. doi: 10.1007/s12160-010-9242-0

Pierce, J. W., \& Wardle, J. (1997). Cause and effect beliefs and self-esteem in overweight children. Child Psychology \& Psychiatry \& Allied Disciplines, 38, 645 - 650. doi: 10.1111/j.1469-7610.1997.tb01691.x

Pollack, A. (2013, June 18). AMA declares obesity a disease. The New York Times. Retrieved from http://www.nytimes.com/2013/06/19/business/ama-recognizes-obesity-as-adisease.html?_r=0

Preacher, K. J., \& Hayes, A. F. (2004). SPSS and SAS procedures for estimating indirect effects in simple mediation models. Behavior Research Methods, Instruments \& Computers, 36, 717 - 731. doi: 10.3758/BF03206553 
Preacher, K. J., \& Hayes, A. F. (2008). Asymptotic and resampling strategies for assessing and comparing indirect effects in multiple mediator models. Behavior Ressearch Methods, 40, 879 - 891. doi: 10.3758/BRM.40.3.879

Puhl, R. M., Andreyeva, T., \& Brownell, K. D. (2008). Perceptions of weight discrimination: Prevalence and comparison to race and gender discrimination in America. International Journal of Obesity, 32, 992 - 1000. doi: 10.1038/ijo.2008.22

Puhl, R. M., \& Brownell, K. D. (2001). Bias, discrimination, and obesity. Obesity Research, 9, 788 - 805. doi: 10.1038/oby.2001.108

Puhl, R. M., \& Brownell, K. D. (2006). Confronting and coping with weight stigma: An investigation of overweight and obese adults. Obesity, 14, $1802-1815$. doi: 10.1038/oby.2006.208

Puhl, R. M., \& Heuer, C. A. (2009). The stigma of obesity: A review and update. Obesity, 17, 941 - 964. doi: 10.1038/oby.2008.636

Puhl, R. M., Moss-Racusin, C. A., Schwartz, M. B., \& Brownell, K. D. (2008). Weight stigmatization and bias reduction: Perspectives of overweight and obese adults. Health Education Research, 23, 347 - 358. doi: 10.1093/her/cym052

Reddy, S. D., \& Crowther, J. H., (2007). Teasing, acculturation, and cultural conflict: Psychosocial correlates of body image and eating attitudes among South Asian women. Cultural Diversity and Ethnic Minority Psychology, 13, 45 - 53. doi: http://dx.doi.org/10.1037/1099-9809.13.1.45

Reynolds, W. M. (1982). Development of reliable and valid short forms of the Marlowe-Crowne Social Desirability Scale. Journal of Clinical Psychology, 38, 119 - 125. doi: 10.1002/1097-4679(198201)38:1<119::AID-JCLP2270380118>3.0.CO;2-I 
Robinson, B., Bacon, L. C., \& O'Reilly, J. (1993). Fat phobia: Measuring, understanding, and changing anti-fat attitudes. International Journal of Eating Disorders, 14, 467 - 480. doi: 10.1002/1098-108X(199312)14:4<467::AID-EAT2260140410>3.0.CO;2-J

Roehling, M. V., Pilcher, S., Oswald, F., \& Bruce, T. (2008). The effects of weight bias on jobrelated outcomes: A meta-analysis of experimental studies. Academy of Management Annual Meeting, Anaheim, CA.

Rosenberger, P. H., Henderson, K. E., Bell, R. L., \& Grilo, C. M. (2007). Associations of weight-based teasing history and current eating disorder features and psychological functioning in bariatric surgery patients. Obesity Surgery, 17, 470 - 477. doi: http://dx.doi.org/10.1007/s11695-007-9082-6

Rudolph, A., \& Hilbert, A. (2015). A novel measure to assess self-discrimination in binge-eating disorder and obesity. International Journal of Obesity, 39, 368 - 370. doi: 10.1038/ijo.2014.89

Rukavina, P. B., Li, W., \& Rowell, M. B. (2008). A service learning based intervention to change attitudes toward obese individuals in kinesiology pre-professionals. Social Psychology of Education, 11, 95 - 112. doi: 10.1007/s11218-007-9039-6

Rukavina, P. B., Li, W., Shen, B., \& Sun, H. (2010). A service learning based project to change implicit and explicit bias toward obese individuals in kinesiology preprofessionals. Obesity Facts, 3, 117 - 126. doi: 10.1159/000302794

Rydell, R. J., \& McConnell, A. R. (2006). Understanding implicit and explicit attitude change: A systems of reasoning analysis. Journal of Personality and Social Psychology, 91, 995 1008. doi: 10.1037/0022-3514.91.6.995 
Seacat, J. D., \& Mickelson, K. D. (2009). Stereotype threat and the exercise/dietary health intentions of overweight women. Journal of Health Psychology, 14, 556 - 567. doi: $10.1177 / 1359105309103575$

Sechrist, G. B., \& Stangor, C. (2005). Social consensus and the origins of stigma. In K. D. Brownell, R. M. Puhl, M. B. Schwartz, \& L. Rudd (Eds.), Weight bias: Nature, consequences, and remedies (pp. 97 - 108). New York: The Guilford Press.

Schvey, N. A., Puhl, R. M., \& Brownell, K. D. (2011). The impact of weight stigma on caloric consumption. Obesity, 19, 1957 - 1962. doi: 10.1038/oby.2011.204

Schwartz, M. B., \& Puhl, R. M. (2005). Summary and concluding remarks. In K. D. Brownell, R. M. Puhl, M. B. Schwartz, \& L. Rudd (Eds.), Weight bias: Nature, consequences, and remedies (pp. 305 - 308). New York: The Guilford Press.

Schwartz, M. B., Vartanian, L. R., Nosek, B. A., \& Brownell, K. D. (2006). The influence of one's own body weight on implicit and explicit anti-fat bias. Obesity, 14, $440-447$. doi: $10.1038 /$ oby.2006.58

Selzer, M. L., Vinokur, A., \& Van Rooijen, L. J. (1975). A self-administered Short Michigan Alcohol Screening Test (SMAST). Studies on Alcohol, 36, 117 - 126.

Sitton, S., \& Blanchard, S. (1995). Men's preferences in romantic partners: Obesity vs. addiction. Psychological Reports, 77, $1185-1186$.

Skinner, H. A. (1982). The Drug Abuse Screening Test. Addictive Behaviors, 7, 363 - 371. doi: $10.1016 / 0306-4603(82) 90005-3$ 
Swift, J. A., Tischler, V., Markham, S., Gunning, I., Glazebrook, C., Beer, C., \& Puhl, R. (2013). Are anti-stigma films a useful strategy for reducing weight bias among trainee healthcare professionals? Results of a pilot randomized control trial. Obesity Facts, 6, 91 - 102. doi: $10.1159 / 000348714$

Teachman, B. A., \& Brownell, K. D. (2001). Implicit anti-fat bias among health professionals: Is anyone immune? International Journal of Obesity, 25, 1525 - 1531. doi: do10.1038/sj.ijo.0801745

Teachman, B. A., Gapinski, K. D., Brownell, K. D., Rawlins, M., \& Jeyaram, S. (2003). Demonstrations of implicit antifat bias: The impact of providing causal information and evoking empathy. Health Psychology, 22, $68-78$.

Teachman, B. A., \& Mallett, R. K. (2005). Measurement of bias. In K. D. Brownell, R. M. Puhl, M. B. Schwartz, \& L. Rudd (Eds.), Weight bias: Nature, consequences, and remedies (pp. 121 - 133). New York: The Guilford Press.

Topolski, T. D., LoGerfo, J., Patrick, D. L., Williams, B., Walwick, J., \& Patrick, M. B. (2006). The Rapid Assessment of Physical Activity (RAPA) among older adults. Preventing Chronic Disease, 3. Retrieved from http://www.cdc.gov/pcd/issues/2006/oct/06_0001.htm

Vartanian, L. R., \& Shaprow, J. G. (2008). Effects of weight stigma on motivation to exercise and exercise behavior: A preliminary investigation among college-aged females. Health Psychology, 13, 131 - 138. doi: 10.1177/1359105307084318

Wang, S. S., Brownell, K. D., \& Wadden, T. A. (2004). The influence of the stigma of obesity on overweight individuals. International Journal of Obesity, 28, 1333 - 1337. doi: 10.1038/sj.ijo.0802730 
Wang, Y., Beydoun, M. A., Liang, L., Caballero, B., \& Kumanyika, S. K. (2008). Will all Americans become overweight or obese? Estimating the progression and cost of the US obesity epidemic. Obesity, 16, 2323 - 2330. doi: 10.1038/oby.2008.351

Weiner, B., Perry, R. P., \& Magnusson, J. (1988). An attributional analysis of reactions to stigmas. Journal of Personality and Social Psychology, 55, 738 - 748. doi: 10.1037/0022-3514.55.5.738

World Health Organization. (2003). Global database on Body Mass Index. Retrieved from http://apps.who.int/bmi/index.jsp?introPage=intro 3.html

World Health Organization (2013, March). 10 facts on obesity. Retrieved from: http://www.who.int/features/factfiles/obesity/en/

Yuker, H. E., \& Block, J. R. (1986). Research with the Attitudes Toward Disabled Persons scales (ATDP) 1960 - 1985. Hempstead, NY, US: Hofstra University 